\title{
A fully-homogenized multiphysics model for a reversible solid oxide cell stack
}

\author{
Navasa, Maria; Miao, Xing-Yuan; Frandsen, Henrik Lund
}

Published in:

International Journal of Hydrogen Energy

Link to article, DOI:

10.1016/j.ijhydene.2019.06.077

Publication date:

2019

Document Version

Peer reviewed version

Link back to DTU Orbit

Citation (APA):

Navasa, M., Miao, X-Y., \& Frandsen, H. L. (2019). A fully-homogenized multiphysics model for a reversible solid oxide cell stack. International Journal of Hydrogen Energy, 44(41), 23330-23347.

https://doi.org/10.1016/j.jijhydene.2019.06.077

\section{General rights}

Copyright and moral rights for the publications made accessible in the public portal are retained by the authors and/or other copyright owners and it is a condition of accessing publications that users recognise and abide by the legal requirements associated with these rights.

- Users may download and print one copy of any publication from the public portal for the purpose of private study or research.

- You may not further distribute the material or use it for any profit-making activity or commercial gain

- You may freely distribute the URL identifying the publication in the public portal

If you believe that this document breaches copyright please contact us providing details, and we will remove access to the work immediately and investigate your claim. 


\title{
A fully-homogenized multiphysics model for a reversible solid oxide cell stack
}

\author{
Maria Navasa ${ }^{\mathrm{a}}$, Xing-Yuan Miao ${ }^{\mathrm{a}}$, Henrik Lund Frandsen ${ }^{\mathrm{a}, *}$ \\ ${ }^{a}$ Department of Energy Conversion and Storage, Technical University of Denmark, Ris $\phi$ Campus, \\ Frederiksborgvej 399, 4000 Roskilde, Denmark
}

\begin{abstract}
In electrochemical devices such as solid oxide cell stacks, many physical phenomena are interacting on many different length scales in an intricate geometry. Modeling is a strong tool to understand the interior of such devices during operation, enhance their design and investigate long-term response (degradation). Computations can however be challenging as the many geometric details and coupled physical phenomena require a significant computational power, and in some cases, even state-of-the-art clusters will not be sufficient. This hinders the use of the models for the further development of the technology. In this work, we present an original type of solid oxide cell stack model, which is highly computationally efficient, resulting in computations which are two orders of magnitude faster than the conventional type of stack models with all geometric details explicitly represented. In the model presented here, the geometric details are implicitly represented by using the so-called homogenization. The resulting homogeneous anisotropic media provides the correct overall response (temperature, species, molar fractions, etc.) Local details as the mechanical stress in the electrolyte are not represented explicitly. These can be retrieved by localization through submodels (multiscale model), in some cases without loss of computational efficiency, as
\end{abstract}

* Corresponding author 
demonstrated.

Keywords: Solid oxide cell, multiphysics, stack modeling, homogenization, computational efficiency, multiscale model

\section{Introduction}

It is undeniable that experiments are essential for providing the decisive validation of a solid oxide cell (SOC) stack concept and its operation mode. However, prototyping, in-situ monitoring, long-term testing, all the necessary fabrication variations from stack to stack, etc., make this an expensive endeavor. To understand possible failures and degradation mechanisms of the stacks, numerical simulations can be used to assist in understanding the observed deterioration and also be able to estimate the conditions for which similar failures in the stack may occur. Nonetheless, the models needed for such tasks should preferably fulfill the following requirements:

1. Reflects and predicts reality well.

2. Computational times are shorter than real times, to be able to study a number of different operation scenarios and long-term effects.

3. Should be able to run on other computational resources than clusters, to be operational for technology providers and not only be an academic endeavor.

Multiphyiscs models are capable of estimating different profiles in the stack, i.e., temperature, pressure drop, stresses, etc. given the operating conditions and so be used to map out "parameter-windows" under which safe operation conditions can be expected. State-of-the-art (SoA) numerical models of SOC stacks usually involve millions of control volumes, elements/degrees of freedom in order to describe all the stack components, e.g., gas channels, manifolds, multiple cell layers, etc. Even with SoA computer clusters, such models are computationally demanding, rather time consuming and effectively challenging to use for the purpose. A typically chosen compromise is to model 
only a repetitive unit of a stack (e.g., one cell, interconnect and frame). Such approach does however limit the model from studying the challenges at the end-plates, where the thermal profile is different from the central part of the stack (where the infinite stack assumption is good). During the last 2-3 decades, a significant number of SOC models at cell level have been developed [1-7] ranging from simple one-dimensional (1D) models to fully-coupled 3D two-potential (ionic and electronic) models describing in detail the variation of the overpotential, partial pressures, temperature, etc., through the cell thickness $[8,9]$. Even at cell level, such complex models are also computationally demanding due to the resolution required in the electrodes. For this reason, assembling analogous cell models into a stack will not fulfill the requirements 2 and 3 stated above.

When going up in scale to model SOC stacks, the first simplification typically made is to avoid describing the ionic charge transfer by a separate potential, i.e., through single potential models. This is done by letting losses related to the ionic charge transfer be part of a total area specific resistance (ASR), including also the reaction kinetics through the activation losses and the concentration losses, and considering only one potential, i.e. the electric potential $[10,11]$. The electrochemical active parts of the cells are thus described by a 2D surface (no thickness) in the 3D stack model. Using this approach, Li et al. [10] have recently shown a fully coupled SOC stack model based on a well-tuned Ansys Fluent model with momentum, mass, species, heat and charge transfer and the electrochemical reactions. Diffusion is taken into account via the Dusty Gas model (DGM). A steady state calculation for a 30 cell stack, with a relatively simple geometry, could be run in 40 hours on a workstation, which is a significant achievement considering the complexity of the model. Longer computational times can however be expected for more complex commercial stack designs and higher number of cells using such approach.

Nishida et al. [11, 12] used the ASR approach and showed better computational performances when computing a steady state model for a 18 and a 100 cell stack under operation conditions using OpenFoam. To increase the computational efficiency, volume averaging of the flow in the cells was utilized. An attractive computational time 
of 60 minutes on a workstation was achieved for the 100 cell stack. Assuming that computational time scales with the number of channels, the model would solve in 40-50 hours (depending on the number of channels), and thus about a factor of $\sim 3$ faster than the model presented by Li et al. (scaling with the number of cells). Furthermore, Nishida et al. were able to show good agreement with experimental data regarding temperature and voltage distributions for an 18 cell stack using the same model [12]. These two reported models certainly fulfill requirement 3 , whereas calculation times of 40 hours makes sweep of many points of operation and long-term simulations very time-consuming.

Another approach is the one taken by Nakajo et al. [6, 13-15] where they study repeating unit cells of a stack. Apart from studying the electrochemical effects, Nakajo et al. have also investigated the mechanical effects in SOC stacks with probably the greatest detail to what has been reported today. Similar studies were also performed by Pianko-Oprych et al. [7, 16] using Ansys Fluent. Dierickx et al. [17] used a 2D repeating unit model built in COMSOL Multiphysics to predict degradation in a stack by coupling such model to a 0D degradation model obtained from experimental data. Also He et al. [18] have used the repeating unit approach to show how a 3D steady state isothermal SOFC stack model can be reduced to a $2 \mathrm{D}$ spatially smoothed one that can capture global and local average properties. While the amount of detail retrievable from this type of models is excellent, challenges near the stack ends cannot be directly described using such models, as thermal gradients, etc. deviate here from a repeating geometry, which would represent an infinite stack.

A large effort in describing many details in the Forschungszentrum Jülich stacks and systems has been undertaken by Peksen et al. [19-21]. The level of detail described in the models is exceptional but the number of degrees of freedom in the Ansys Fluent models makes it challenging to extend such studies to be time-dependent and fully-coupled (heat, mass, electrochemistry, etc.) as already in the current version considering heat, flow and solid mechanics, a large cluster is required to perform the simulations. 
To increase the computational speed of the SOC stack models, porous media type of models to simplify the flow domain have been utilized over the years. Actually, already the first SOFC stack models by Achenbach, Costamagna, Hendriksen and others [2225] provided a simple equivalent flow resistance based on the geometry of the channels, their hydraulic diameter, etc. for each computational cell. More recently, the approach was also used by Nishida et al. [11], Beale and Zhubrin [26] and Al-Masri et al. [27] in modern computational fluid dynamics (CFD) codes such as OpenFOAM and Ansys Fluent by replacing the flow channels by porous media, see Fig. 1. In these models, each repeating unit consists of 4 layers of representative volumes, i.e., 2 for the fuel and air channels (porous domains), 1 for the interconnect and 1 for the cell. Therefore, a stack model of $\mathrm{N}_{\text {cells }}$ number of cells needs, at least, $4 \mathrm{~N}_{\text {cells }}$ layers of computational volumes. A similar approach is taken by Kvesić et al. [28] for modeling polymer electrolyte fuel cells, where they further reduced the number of computational volumes to two per repeating unit cell layer.

To retrieve the equivalent flow resistance in these works by Beale et al. [26, 27], socalled homogenization is applied. This approach is a general concept used in different fields like biological tissues, composite materials, optics and acoustics (wave equations), porous media, interfaces and transmission problems, etc. [29-32]. The homogenization approach is useful to describe a geometrically detailed geometry with repeating units, and in particular, when this is challenging the computational resources available. The idea behind this approach is to replace the regions with repeating geometric details by an equivalent homogeneous medium, whose behavior represents the average behavior of the composite at macroscopic scale.

A step further into decreasing the computational cost, by decreasing the amount of details explicitly accounted for, has been taken in this work by homogenizing the entire repeating unit. Here, a computationally efficient fully-coupled multiphysics model of a SOC stack considering momentum, mass, species, heat and charge transfer, the electrochemical reactions and mechanical stresses is presented. The main development is utilizing the homogenization approach on all layers in an SOC stack for all the physics 
mentioned, so that the model only consists of one type of computational volumes. Several repeating units in a stack can thus be contained within a single computational volume, such that the number of computational volumes in the out-of-cell plane direction can be lower than the number of cells $\mathrm{N}_{\text {cells }}$, see Fig. 1. This model allows for fast full stack simulations and is also believed to be suitable for long-term operation studies. Moreover, calculations can be run on ordinary computers, without the need for clusters. A steady state operation simulation on a 100 cell stack operating in electrolysis mode can be completed in $\sim 14$ minutes on a workstation. The main purpose of this article is to present this computational advantageous method, while using simple geometry, reaction kinetics and boundary conditions. The output of the model is illustrated using different examples on results from the model together with the computational times to illustrate the efficiency.

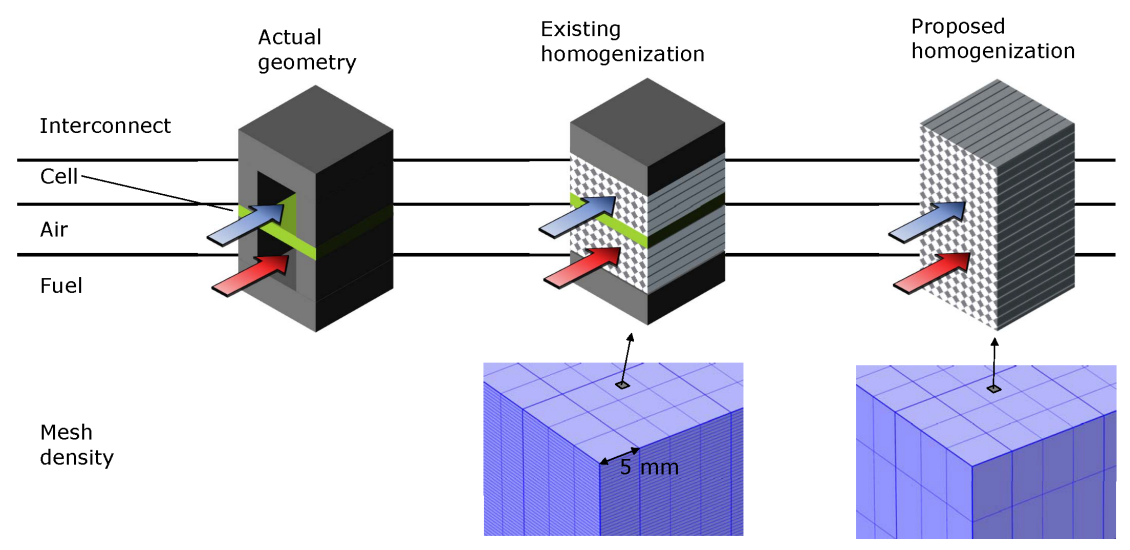

Figure 1: Current homogenization approaches in SOC modeling compared to an actual geometry. The existing homogenization approach by Nishida et al.[11] - homogenization of the gas channels, compared to the fully-homogenized repeating element proposed here.

\section{Model description}

The 3D stack model is constructed using the homogenization approach, in which the different interior sub-components of the stack (i.e., cells, gas channels, etc.) are 
described with a single computational volume, effectively describing the response of them all. This gives the advantage that the detailed geometry is only implicitly described, and with far less computational time and cost. We exemplify the use of the homogenization approach for an electrochemical device on a simple SOC stack with a geometry and operational conditions relevant to those of a real SOC stack. The current version of the model is steady state, but as seen as follows, conventional partial differential equations are used, which can all be formulated as time-dependent. In this section, the stack geometry considered in the model and how the homogenization approach is used with the governing equations and boundary conditions to represent the SOC stack are presented. The equations described in this work have been solved with the finite element method (FEM) based commercial software COMSOL Multiphysics 5.4 .

\subsection{Stack geometry}

An SOC stack is per se a complex energy conversion unit not only due to the number of components involved, but also as a result of the different phenomena occurring simultaneously, coupled and at different length scales. A figurative description of the homogenization approach is that the active part of the stack, which includes solid domains and channels where gases diffuse through, is represented by a porous medium.

The geometry used to simulate the stack behavior is shown in Figure 2. In Fig. 2 b) a 10 by $10 \mathrm{~mm}^{2}$ cut-out of a 10 cell stack with all internal components is shown, and by its side, the whole stack with a homogenized geometry (porous medium), which is the geometry used for the calculations in this work. In Fig. 2 c), two domains can be distinguished. One domain is the cuboid representing the stack (in ocher) and the other is the sealing surrounding the stack (in grey). The stack shown has an active area of $100 \mathrm{~cm}^{2}$ and a stack height equivalent to the height of 100 repeating units. The cut-out only shows 10 repeating units. The geometry parameters used for the example given in this work are shown in Table 1. 


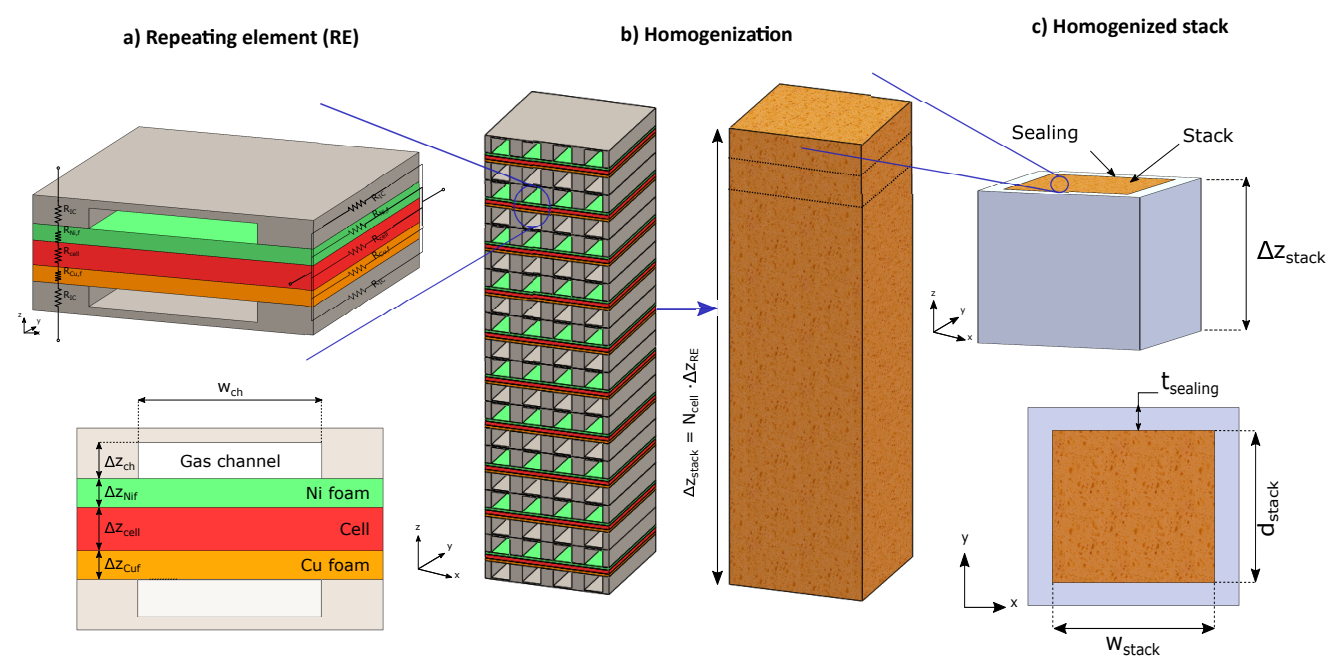

Figure 2: The stack geometry and homogenization: a) Repeating element of active part of the SOC stack in $3 D$ and cross-section, b) 10 repeating elements stacked and the equivalent homogenous media and c) Homogenized stack with two domain; active domain and manifold domain in $3 D$ and a top-view.

As noticed in Fig. 2, in the stack simulation domain, i.e., the homogenized stack, the cells, gas flows, etc. are all represented by an effective porous media. A detail of the geometry considered for representing the stack in an effective manner is shown in Fig. 2 a). A stack is composed by a certain number of repeating units with a single cell in each. Each repeating unit with a single cell and interconnect can be sub-divided into a number of repeating elements (RE) with the width of a single channel plus the channel's rib. The repeating element used in this work is comprised of a nickel foam, a copper-manganese spinel foam, two half-interconnects, as well as two gas channels; one for the fuel and the other for the air and the cell itself, which is composed of a fuel electrode, an electrolyte and an air electrode. The repeating element is used later on for calculating the necessary effective properties to implement the homogenization approach for the different transport phenomena considered. 
Table 1: Geometry parameters

\begin{tabular}{lcc}
\hline Parameter & Value & Units \\
\hline Number of cells $\left(\mathrm{N}_{\text {cells }}\right)$ & 100 & - \\
Stack width $\left(\mathrm{w}_{\text {stack }}\right)$ & 10 & $\mathrm{~cm}$ \\
Stack depth $\left(\mathrm{d}_{\text {stack }}\right)$ & 10 & $\mathrm{~cm}$ \\
Sealing thickness $\left(\mathrm{t}_{\text {sealing }}\right)$ & 15 & $\mathrm{~mm}$ \\
Ni foam thickness $\left(\Delta \mathrm{z}_{\mathrm{Ni}, \mathrm{f}}\right)$ & 200 & $\mu \mathrm{m}$ \\
Cu foam thickness $\left(\Delta \mathrm{z}_{\mathrm{Cu}, \mathrm{f}}\right)$ & 200 & $\mu \mathrm{m}$ \\
Interconnect thickness $($ half $)\left(\Delta \mathrm{z}_{\mathrm{IC}}\right)$ & 100 & $\mu \mathrm{m}$ \\
Cell height $\left(\Delta \mathrm{z}_{\mathrm{cell}}\right)$ & 300 & $\mu \mathrm{m}$ \\
Channel height $\left(\Delta \mathrm{z}_{\mathrm{ch}}\right)$ & 250 & $\mu \mathrm{m}$ \\
Channel width $\left(\mathrm{w}_{\mathrm{ch}}\right)$ & 1.5 & $\mathrm{~mm}$ \\
Repeating element width $\left(\mathrm{w}_{\mathrm{RE}}\right)$ & 2.5 & $\mathrm{~mm}$ \\
Repeating element depth $\left(\mathrm{d}_{\mathrm{RE}}\right)$ & 2.5 & $\mathrm{~mm}$ \\
\hline
\end{tabular}

\subsection{Homogenization}

Homogenization is useful when a numerical or a detailed analysis of a large number of heterogeneous regions becomes unfeasible. The idea behind this approach is to replace the different regions with geometric details by an equivalent homogeneous medium whose behavior represents the average behavior of the heterogeneous regions at macroscopic scale.

\section{Averaged parameters}

For implementing the homogenization approach, it is necessary to calculate parameters representing the average behavior of the composite material. Different ways exist for calculating averaged parameters, but a common one is to calculate volume-averaged values [33, 34], see Eq. (1). 


$$
\bar{p}=\frac{1}{|\Omega|} \int_{\Omega} p \mathrm{~d} \Omega
$$

where $\bar{p}$ is the averaged parameter, $p$ the parameter and $\Omega$ is the volume of the repeating element.

To illustrate the method, the calculation of an averaged thermal conductivity is used here as an example on the use of the homogenization approach on a SOC stack. The same procedure can be used for calculating averaged values of different parameters.

As the different stack components are not explicitly represented in the homogenization approach, an equivalent anisotropic thermal conductivity that takes into account the effect of the different layers and materials in the different directions is necessary, Eq. (2).

$$
\overline{\boldsymbol{k}}=\left[\begin{array}{ccc}
\bar{k}_{x} & 0 & 0 \\
0 & \bar{k}_{y} & 0 \\
0 & 0 & \bar{k}_{z}
\end{array}\right]
$$

The components of the thermal conductivity in the different axes are obtained by implementing Eq. (1). Yet, in heat transfer, this approach is also known as setting up equivalent thermal resistance circuits in such directions for the repeating element unit. The concept is the same as they are volume-averaged calculations of the material properties. If the repeating element geometry is too complex to be able to calculate an equivalent thermal resistance analytically, computational models can be used [35-40].

For the case being, thermal resistance circuits in the $y$ - and $z$-axes have been drawn for the repeating element, see Fig. 2 a) top. From Fig. 2 it is clear that for the $x$ - and $y$-axes, the equivalent thermal resistances is the sum of thermal resistances in parallel and Eq. (3) applies, while for the $z$-axis, this is a sum of thermal resistances in series 
and Eq. (4) is valid.

$$
\begin{gathered}
\frac{1}{R_{x, y}}=\frac{\bar{k}_{x, y} A_{x, y}}{\Delta \mathrm{z}}=\sum_{i=1}^{n} \frac{1}{R_{i}}=\sum_{i=1}^{n} \frac{k_{i} A_{i}}{\Delta \mathrm{z}_{i}} \\
R_{z}=\frac{\Delta \mathrm{z}}{\bar{k}_{z} A_{z}}=\sum_{i=1}^{n} R_{i}=\sum_{i=1}^{n} \frac{\Delta \mathrm{z}_{i}}{k_{i} A_{i}}
\end{gathered}
$$

where $\Delta \mathrm{z}_{i}$ is the thickness, $k_{i}$ the thermal conductivity and $A_{i}$ the cross-sectional area perpendicular to the direction of conduction in the $i$ th layer.

Substituting terms and rearranging Eq. (3) for the repeating element shown here, the equivalent thermal conductivity in the $x$-axis and $y$-axis, can be calculated as:

$$
\begin{gathered}
\bar{k}_{x}=\frac{2 k_{\mathrm{steel}} \Delta \mathrm{z}_{\mathrm{IC}}+k_{\mathrm{Ni}, \mathrm{f}} \Delta \mathrm{z}_{\mathrm{Ni}, \mathrm{f}}+k_{\mathrm{cell}} \Delta \mathrm{z}_{\mathrm{cell}}+k_{\mathrm{Cu}, \mathrm{f}} \Delta \mathrm{z}_{\mathrm{Cu}, \mathrm{f}}}{\Delta \mathrm{z}_{\mathrm{RE}}} \\
\bar{k}_{y}=\frac{2 k_{\mathrm{steel}}\left(\Delta \mathrm{z}_{\mathrm{IC}}-\Delta \mathrm{z}_{\mathrm{ch}} \frac{\mathrm{w}_{\mathrm{ch}}}{\mathrm{w}_{\mathrm{RE}}}\right)+k_{\mathrm{Ni}, \mathrm{f}} \Delta \mathrm{z}_{\mathrm{Ni}, \mathrm{f}}+k_{\mathrm{cell}} \Delta \mathrm{z}_{\mathrm{cell}}+k_{\mathrm{Cu}, \mathrm{f}} \Delta \mathrm{z}_{\mathrm{Cu}, \mathrm{f}}}{\Delta \mathrm{z}_{\mathrm{RE}}}
\end{gathered}
$$

It should be pointed out that if the stack flow configuration was different, i.e., cross-flow instead of co-flow, the values of $\bar{k}_{x}$ and $\bar{k}_{y}$ would be different than the ones specified here, as the cross-sectional areas are different.

Following the same procedure, the equivalent thermal conductivity for the $z$-axis is:

$$
\bar{k}_{z}=\frac{\Delta \mathrm{z}_{\mathrm{RE}}}{2 \frac{\Delta \mathrm{z}_{\mathrm{ch}}}{k_{\text {steel }}} \frac{\mathrm{w}_{\mathrm{RE}}}{\left(\mathrm{w}_{\mathrm{RE}}-\mathrm{w}_{\mathrm{ch}}\right)}+2 \frac{\Delta \mathrm{z}_{\mathrm{IC}}}{k_{\text {steel }}}+\frac{\Delta \mathrm{z}_{\mathrm{Ni}, \mathrm{f}}}{k_{\mathrm{Ni}, \mathrm{f}}}+\frac{\Delta \mathrm{z}_{\mathrm{cell}}}{k_{\mathrm{cell}}}+\frac{\Delta \mathrm{z}_{\mathrm{Cu}, \mathrm{f}}}{k_{\mathrm{Cu}, \mathrm{f}}}}
$$




\subsection{Governing equations}

The different equations considered in this work for simulating the different physical phenomena in SOC stacks are presented here. Details on how homogenization has been applied to model the different phenomena are also outlined.

\section{Momentum and mass transfer}

Despite the channels are the most permeable parts of the stack, other stack components such as the electrodes and the contact layers may also be available to gas transport. For modeling an SOC stack, two different gases should be considered; an air or oxygen flow and a fuel or feedstock flow.

Basically, the homogenized model should represent the same average flow field for a given pressure drop across the stack as the real stack. As the flow in the channels and

in the porous media (if any) are known to be laminar, $R e_{\text {air }}<150$ for the calculations shown here, then the velocity is known to be proportional to the pressure drop:

$$
\mathbf{U}=-\frac{\kappa}{\mu} \nabla p
$$

which is Darcy's law for flow in porous media.

Conceptually, this also makes sense as channels in an averaged sense can be considered as oriented macro-pores in the SOC stack. The orientation of the flow can be captured by letting $\kappa$ be a tensor describing the orthotropic effective permeabilities [41]. The effective permeability can be achieved by modeling the flow through actual repeating arbitrary channel geometry for different pressure drops.

In some designs, the flow path is relatively tortuous and topology optimization is 
required for a homogenized description [42]. However, most of the current industrial interconnect designs have straight channels providing a uniform fuel distribution across the active area allowing for a high fuel utilization.

In this work, straight channels with rectangular cross-sectional area design will be used to present the modeling concept, as we here can derive a simple and easily understandable analytic representation of the effective permeabilities, see Fig. 2. Any channel geometries can be used for computational modeling of the effective permeability (will be shown in the following works).

Thus, the flow through the stack can be described as the flow through a straight rectangular channel. The pressure drop for a gas flow with mean velocity $u$ along the flow direction through a straight channel and under laminar regime, can be described by the Darcy-Weisbach equation:

$$
\frac{\mathrm{d} p}{\mathrm{~d} x}=-f_{D} \frac{\rho u^{2}}{2 D_{h}}=-\frac{2 \mu g_{c}}{D_{h}^{2}} u
$$

where $f_{D}$ is Darcy's friction factor and equal to $f_{D}=4 g_{c} / R e . R e$ is the Reynolds number $\left(R e=\rho u D_{h} / \mu\right)$, where $\rho$ and $\mu$ are the density and the viscosity of the gas and $D_{h}$ is the hydraulic diameter of the gas channel. $g_{c}$ is a correction factor related to the channel shape. For a channel with a rectangular cross-sectional area like the one used in this work, the correction factor is [43]:

$$
\begin{aligned}
g_{c}=24 & \left(1-1.3553 g_{a}+1.9467 g_{a}^{2}-1.7012 g_{a}^{3}\right. \\
+ & \left.0.9564 g_{a}^{4}-0.2537 g_{a}^{5}\right)
\end{aligned}
$$

where $g_{a}=\min \left(\frac{\mathrm{w}_{\mathrm{ch}}}{\Delta \mathrm{z}_{\mathrm{ch}}}, \frac{\Delta \mathrm{z}_{\mathrm{ch}}}{\mathrm{w}_{\mathrm{ch}}}\right)$. 
By comparing Equations (8) and (9), the effective permeability for the stack with rectangular channels - in the flow direction $(y)$, is found to be:

$$
\kappa=\frac{D_{h}^{2}}{2 g_{c}}
$$

For the chosen geometry, the permeabilities in the other directions are zero (no flow).

Besides Darcy's law, the continuity equation is also needed to describe the flow in porous media, Eqs. (8) and (12).

$$
\nabla \cdot(c \mathbf{U})=S_{m}
$$

where $c$ is the molar density, $\kappa$ the permeability, $\mathbf{U}$ the velocity and $S_{m}$ is the mass source term. The molar density is defined as the moles of the given gas mixture over the entire volume of the small repeating element, $\Omega$, i.e., the volume including interconnect, cells, porous media and both flow channels, although the given species are not physically present everywhere. This is very important for the conceptual understanding of the model.

Modeling wise, the stack can thus be considered as a reactor with the reactive species and products well mixed into each other. The reaction rates between the mixed species are set by the area specific resistance (ASR), the species concentrations, temperature, etc. The reactants (fuel and air) appear homogeneously over the entire repeating element as well. This is described mathematically through the molar (volumetric) source terms/sinks for species $i, S_{m, i}$, which is defined as follows:

$$
S_{m, i}=\frac{1}{n_{e} F} i_{\Omega}=\frac{1}{n_{e} F} \frac{i_{z}}{\Delta \mathrm{z}_{\mathrm{RE}}}
$$


where $n_{e}$ is the number of electrons transferred per molecule of reactant in the repeating unit, $F$ is the Faraday constant, $\Delta \mathrm{z}_{\mathrm{RE}}$ the height of the repeating element and $i_{\Omega}$ the volumetric current density (which depends on the ASR, see Section 2.3). With the reactor analogy, it becomes clear that the volumetric current density is simply the area based current density, $i_{z}$, divided by the height of the repeating element, $\Delta \mathrm{z}_{\mathrm{RE}}$.

As pointed out in this homogenization approach, the entire volume of the repeating element, $\Omega$, is available for the gas flow (i.e., interconnects, cell, channels, etc.) while in the real stack, the air and the fuel only occupy the flow volume in their respective channels, $\Omega_{\mathrm{ch}}$. Modeling wise, this means that the gases are "diluted" by the ratio of volumes, $\Omega_{\mathrm{ch}} / \Omega$, and that the gas densities at the inlet of the stack should be set accordingly, as the entire side of the stack in this modeling concept is available for inflow.

In the current version of the model, the manifolds are not explicitly represented, and we assume that the flow enters at the boundary of the active volume. This is of course an approximation, but here we focus on presenting the homogenization approach in a simple manner.

\section{Mass conservation and diffusion of species}

Besides the continuity equation, Eq. (12), which considers the bulk flow within the stack, the different species constituting the gas flows also experience motion relative to each other due to different concentration gradients across the stack. In the homogenization framework it is not possible to resolve concentration gradients within the repeating unit. Thus, the diffusion described here is within the gas-channels and not within the porous electrodes. The diffusion within the porous electrodes is handled by using a concentration overpotential in the ASR expression, as explained in Section 2.3. If the flow in an SOC is a multicomponent system with a mixture of $n$ species, a balance equation for $n-1$ components is required, Eq. (14). 


$$
\nabla \cdot\left(c \mathbf{U} Y_{i}\right)=-\nabla \cdot \mathbf{N}_{i}+S_{m, i}
$$

where $Y_{i}$ is the molar fraction, $\mathbf{N}_{\mathrm{i}}$ is the molar diffusion flux of species and $S_{m, i}$ is the source term due to the electrochemical reaction for species $i$, Eq. (13).

Mass diffusion is complex by definition and especially in systems like solid oxide cells and stacks where active porous electrodes are present [44]. In this model, mass diffusion in the channels is accounted for as stated in Navasa et al. [8], i.e., an effective diffusion coefficient is obtained via the Bosanquet equation accounting for Knudsen diffusion and molecular diffusion, calculated through the Stefan-Maxwell model. Although diffusion is in this manner represented in the channels, the dominating mass transport mechanism here is convection.

As mentioned above, the gases in the model are occupying the entire unit cell. Thus, the concentrations are lower than in the real stack, but the cross-section computationally available for mass diffusion transport is correspondingly larger, and the mass flux by diffusion is then correctly described.

The mass balances in the convective mass transport are also ensured by having a lower density to compensate for that the mass flux takes place through the entire homogeneous cross-section of the stack.

\section{Heat transfer}

Heat management in an SOC stack is complex due to the different heat transfer mechanisms taking place at different levels and components. Overall, energy should be conserved throughout the whole computational domain via the energy conservation equation: 


$$
\nabla \cdot\left(\rho c_{p} \mathbf{U T}\right)=\nabla \cdot(\mathbf{k} \nabla \mathrm{T})+S_{\mathrm{T}}
$$

where $\rho$ and $c_{p}$ are the density and the specific heat at constant pressure of the gas mixture, respectively, $\mathbf{k}$ is the thermal conductivity of the medium, $\mathrm{T}$ the temperature and $S_{\mathrm{T}}$ is the heat source term.

To account for separate temperatures of the solids and the two gas streams, the energy conservation equation should be applied three times, with the three temperatures being independent variables. In reality, heat is exchanged between the solids and the gases, and the three equations are thus coupled with each other through convective heat transfer at the surfaces.

With the homogenization approach, all three temperatures are defined everywhere in the computational domain, and heat can be exchanged at every point in the model. The exchange rates depend on the surface areas in the real geometry, through which the heat is exchanged, temperature differences, Nusselt number, etc. are described as follows. As the channels' surfaces are part of the effective porous media describing the interior of the stack, the heat transfer due to convection occurs everywhere in the repeating element and is taken into account using a volumetric source term, $S_{T}^{c}$. This term should thus describe the amount of heat exchanged through the surfaces, $A_{\mathrm{ch}}$, in the volume of a repeating element, $\Omega$ :

$$
S_{\mathrm{T}}^{c}=h \frac{A_{\mathrm{ch}}}{|\Omega|}\left(T_{\text {solids }}-T_{\text {gas }}\right)
$$

where $h$ is the convective heat transfer coefficient and $A_{\mathrm{ch}}$ is the convective heat transfer area, which is the area of the solid domain being wet by the specific gas (the channels' surface areas) per volume of repeating element, $\Omega$. For the square channels, used here as an example, it becomes: 


$$
\frac{A_{\mathrm{ch}}}{|\Omega|}=\frac{2\left(\mathrm{w}_{\mathrm{ch}}+\mathrm{h}_{\mathrm{ch}}\right) \mathrm{d}_{\mathrm{RE}}}{\mathrm{w}_{\mathrm{RE}} \mathrm{d}_{\mathrm{RE}} \Delta \mathrm{z}_{\mathrm{RE}}}=\frac{2\left(\mathrm{w}_{\mathrm{ch}}+\mathrm{h}_{\mathrm{ch}}\right)}{\mathrm{w}_{\mathrm{RE}} \Delta \mathrm{z}_{\mathrm{RE}}}
$$

The convective heat transfer coefficient, $h$, can be obtained via the Nusselt number, $\mathrm{Nu}=h D_{h} / k_{\text {gas }}$ [45], where Eq. (16) can be rewritten as:

$$
S_{\mathrm{T}}^{c}=\frac{\mathrm{Nu} k_{\text {gas }}}{D_{h}} \frac{A_{\mathrm{ch}}}{|\Omega|}\left(T_{\text {solids }}-T_{\text {gas }}\right)
$$

For a rectangular channel with fully-developed laminar flow, like in the treated SOC stack, the Nusselt number becomes a constant. For the dimensions and conditions specified here, $\mathrm{Nu}=3.3$ [45]. The source term, Eq. (18), is implemented in the two gaseous domains, i.e., the fuel and the oxygen, separately, and in the solid stack components - with opposite signs in the solids and the gases (energy conservation).

For conduction in the solids, the average thermal conductivity of the solid phases representing the stack, $\bar{k}$, is calculated as shown in Section 2.2, Eqs. (5) to (7).

The heat source term, $S_{T}^{r}$, accounts for the reaction heat and various losses from the electrochemical reactions and ohmic losses due to charge transfer. The following amount of heat is generated in every point of the model distributed evenly over the height of each repeating element $\Delta \mathrm{z}_{\mathrm{RE}}$.

$$
\begin{aligned}
S_{\mathrm{T}}^{r}= & \frac{1}{\Delta \mathrm{z}_{\mathrm{RE}}}\left(\frac{i_{z} T \Delta S}{2 F}+i_{z}^{2} \mathrm{ASR}\right) \\
= & \frac{i_{z}}{\Delta \mathrm{z}_{\mathrm{RE}}}\left(\frac{T \Delta S}{2 F}+i_{z} \mathrm{ASR}\right)
\end{aligned}
$$

where $\Delta S$ is the entropy change for the reaction, $F$ Faraday's constant, $i_{z}$ the current density and ASR is the area specific resistance and is further described in ??. As this 
heat is evolved through the thickness of the cell, the heat source is added to those in the solid phases.

The heat produced or consumed depends on the balance between the two terms in Eq. (19). In steam electrolysis, the reaction heat is negative and will, at some point, balance the contributions from the second term, i.e. at thermo-neutral operation.

It must be pointed out that the heat source term, $S_{T}^{r}$, is per volume, and thus it is necessary to divide the current density by the height to make it volumetric. For the homogenization approach, this height corresponds to the height of the repeating element or unit.

It is also important to notice that in the homogenization approach the heat sources are equally distributed within the repeating unit. This is a reasonable assumption as the heat transport across the very small distance of cell is much faster as compared to the longer distances in the cell plane.

Summarizing, the three heat source terms accounting for both convective heat transfer, $S_{\mathrm{T}}^{c}$, and reactions, $S_{\mathrm{T}}^{r}$, become:

$$
\begin{aligned}
S_{\mathrm{T}}= & S_{\mathrm{T}}^{r}+S_{\mathrm{T}}^{c} \\
S_{\mathrm{T}}^{\text {fuel }}= & h \frac{A_{\mathrm{ch}}}{|\Omega|}\left(T_{\text {solids }}-T_{\text {fuel }}\right) \\
S_{\mathrm{T}}^{\text {air }}= & h \frac{A_{\mathrm{ch}}}{|\Omega|}\left(T_{\text {solids }}-T_{\text {air }}\right) \\
S_{\mathrm{T}}^{\text {solids }}= & -h \frac{A_{\text {ch }}}{|\Omega|}\left(T_{\text {solids }}-T_{\text {fuel }}\right)-h \frac{A_{\text {ch }}}{|\Omega|}\left(T_{\text {solids }}-T_{\text {air }}\right) \\
& +\frac{i_{z}}{\Delta \text { z }_{\mathrm{RE}}}\left(\frac{T \Delta S}{2 F}+i_{z} \mathrm{ASR}\right)
\end{aligned}
$$




\section{Charge transport}

The voltage difference, $\Delta V$, over a repeating element of height $\Delta z_{\mathrm{RE}}$, i.e., the cell voltage, can be expressed as:

$$
\Delta V=E-i_{z} \mathrm{ASR}
$$

where $i_{z}$ is the current in the $z$ direction (out-of-plane), $E$ is the cell open circuit voltage and ASR is the area specific resistance, which includes the different resistances in the repeating element as previously specified (diffusion, ohmic losses, charge transfer, etc.).

By adding the voltage differences for each repeating element in the stack height, the stack voltage can be obtained. The average change in potential over the height is then $\Delta V / \Delta z$ and for the homogenized stack, the corresponding potential gradient in the $z$ direction becomes $\partial V / \partial z=\Delta V / \Delta z$. Inserting this expression into Eq. (24) and rearranging, yields:

$$
i_{z}=\frac{E}{\operatorname{ASR}}-\frac{\Delta \mathrm{zRE}_{\mathrm{RE}}}{\operatorname{ASR}} \frac{\partial V}{\partial z}
$$

The cell open circuit voltage, $E$, is defined as:

$$
\begin{array}{r}
E=\pi_{\text {air }}^{\text {eq }}-\pi_{\text {fuel }}^{\text {eq }}=\frac{\frac{1}{2} \mu_{\mathrm{O}_{2}}^{*}+\mu_{\mathrm{H}_{2}}^{*}-\mu_{\mathrm{H}_{2} \mathrm{O}}^{*}}{2 F}+\frac{R T}{2 F} \ln \left(\frac{a_{\mathrm{H}_{2}} a_{\mathrm{O}_{2}}^{\frac{1}{2}}}{a_{\mathrm{H}_{2} \mathrm{O}}}\right)= \\
=\frac{\Delta G_{r x, \mathrm{H}_{2} \mathrm{O}}}{2 F}+\frac{R T}{2 F} \ln \left(\frac{p_{\mathrm{H}_{2}} p_{\mathrm{O}_{2}}^{\frac{1}{2}}}{p_{\mathrm{H}_{2} \mathrm{O}} p^{\ominus^{\frac{1}{2}}}}\right)
\end{array}
$$

where $\pi_{\text {air }}^{\mathrm{eq}}$ and $\pi_{\text {fuel }}^{\mathrm{eq}}$ are the electromotive potentials at equilibrium for each electrode, 
$\mu_{i}^{*}$ is the chemical potential of species $i$ at a reference state, $a_{i}$ is the activity of the component $i$ in the correspondent gas mixture, $\Delta G_{r x, \mathrm{H}_{2} \mathrm{O}}$ is the Gibbs energy change for the water splitting reaction, $p_{i}$ is the partial pressure of the component $i$ in the correspondent gas mixture and $p^{\ominus}$ is the standard pressure (1 atm).

$\Delta G_{r x, \mathrm{H}_{2} \mathrm{O}}$ is implemented as function of temperature, see Appendix A in [8].

Any expression for the ASR can be included in this modeling framework. Here, we have chosen to include the model by Leonide et al. [46], which is a rather complete expression including a fitted closed form expression for the concentration overpotential, $\eta_{c o n c}$, and the activation overpotential, $\eta_{a c t}$, for both electrodes as well as an expression for the Ohmic overpotential, $\eta_{O h m}$. Overall, the cell voltage, $\Delta V$, can be also expressed as:

$$
\Delta V=E-\left(\eta_{O h m}+\eta_{a c t, o}+\eta_{a c t, f}+\eta_{c o n c, o}+\eta_{c o n c, f}\right)
$$

where $o$ and $f$ denote the oxygen and fuel electrodes, respectively. The diffusion into the electrodes is thus modeled by a concentration overpotential, as mentioned previously. Comparing Eq. (24) and Eq. (27), the ASR is as follows:

$$
A S R=\frac{\eta_{O h m}+\eta_{a c t, o}+\eta_{a c t, f}+\eta_{c o n c, o}+\eta_{c o n c, f}}{i_{z}}
$$

To this ASR, another additional $0.2 \Omega \mathrm{cm}^{-2}$ have been added accounting for the resistance of the stack, i.e., resistance from interconnectors, coatings, in-plane conduction of current through the contact layers for current collection, etc.

The current should also be conserved throughout the computational domain: 


$$
\nabla \cdot \mathbf{i}=0
$$

where $\mathbf{i}$ is the total current density flux, consisting of the current generated by the electrical field and the external current density. For the out-of-plane direction $(z-$ direction), Eq. (29) becomes:

$$
\frac{\partial}{\partial z}\left(\frac{E}{\operatorname{ASR}}-\frac{\Delta \mathrm{z}_{\mathrm{RE}}}{\operatorname{ASR}} \frac{\partial V}{\partial z}\right)=0
$$

Then, $E / A S R$ can be identified as the external current density and $\Delta \mathrm{z}_{\mathrm{RE}} / \mathrm{ASR}$ as the conductivity in the $z$-direction.

In the cell plane, $x$ - and $y$-directions, there is no "external current" generated, and the conductivity, $\gamma$, is the average of the unit cell, i.e., primarily that of the interconnect, which is far higher than the out-of-plane conductivity. Equation (29) thus becomes:

$$
\begin{aligned}
& \frac{\partial}{\partial x}\left(-\gamma_{x} \frac{\partial V}{\partial x}\right)=0 \\
& \frac{\partial}{\partial y}\left(-\gamma_{y} \frac{\partial V}{\partial y}\right)=0
\end{aligned}
$$

The orthotropic conductivity is thus:

$$
\gamma=\left[\begin{array}{ccc}
\gamma_{x} & 0 & 0 \\
0 & \gamma_{y} & 0 \\
0 & 0 & \frac{\Delta \mathbf{z}_{\mathrm{RE}}}{\mathrm{ASR}}
\end{array}\right]
$$


And the external current density vector equals:

$$
\mathbf{i}_{e}=\left[\begin{array}{c}
0 \\
0 \\
\frac{E}{\mathrm{ASR}}
\end{array}\right]
$$

In short, the charge transfer equation can be re-written as:

$$
\nabla \cdot(\gamma \nabla V)=\nabla \cdot \mathbf{i}_{e}
$$

Notice that for a single cell stack, all the partial differential equations (PDEs) presented above basically simplify to the simpler expressions used in the models by Achenbach and his peers [22-25]. However, having these models formulated as PDEs makes it possible to implement them in modern PDE solvers, such as Comsol Multiphysics, where the model becomes independent of the mesh. This is a great advantage as several cell layers can be covered by a single finite element or control volume (if CFD is used). Hereby, a 100 cell stack can easily be modeled by far less elements - conventional homogenization like in [28] would require $\sim 400$ layers of elements, here we use 13. The mesh density should then be chosen according to the gradients of the free variables that are solved for (for an accurate solution).

\section{Mechanical stresses}

Modeling mechanical behavior of a solid oxide cell stack is key for understanding failures and optimizing the SOC stack designs. Tensile stresses might lead to cracking in the brittle cell or delamination between the interfaces, such sealing failure or contact loss between them [47-50]. Fractures will lead to immediate failure or rapid degradation as they are resulting in mixing of fuel and oxidants or involve heating due to tortuous charge transfer. 
Stresses induced by the temperature field and boundary constraints (e.g. external loads) are incorporated into the stack model in the framework of linear elasticity. Also here homogenization can be used to effectively describe the overall mechanical response of the stack. The stresses and strains calculated over the homogeneous equivalent model represent the macroscopic mechanical behaviors of the stack, and are called effective/volume averaged stresses, $\bar{\sigma}$, and strains, $\bar{\epsilon}$. These are calculated as for a simple anisotropic elastic media, using Hook's law:

$$
\overline{\boldsymbol{\sigma}}=\overline{\boldsymbol{C}}:\left(\overline{\boldsymbol{\epsilon}}-\overline{\boldsymbol{\epsilon}}_{\mathrm{T}}\right)
$$

with

$$
\overline{\boldsymbol{\epsilon}}_{\mathrm{T}}=\overline{\boldsymbol{\alpha}}\left(T-T_{r e f}\right)
$$

where $\bar{\sigma}$ is the stress tensor, $\overline{\boldsymbol{\epsilon}}$ is the total strain tensor, $\overline{\boldsymbol{\epsilon}}_{\mathrm{T}}$ is the thermal strain tensor, $\bar{C}$ is the stiffness tensor describing the equivalent anisotropic stiffness of a homogeneous media, $\bar{\alpha}$ is the linear thermal expansion tensor and $T$ stands for temperature and $T_{r e f}$ for the reference temperature (zero stress temperature).

The volume averaged components $\bar{C}_{i j}$ of the stiffness tensor, $\bar{C}$, can be retrieved by a numerical model of the geometry [51].

$$
\bar{C}_{i j}=\frac{1}{|\Omega|} \int_{\Omega} C_{i j} \mathrm{~d} \Omega
$$

And the thermal expansion coefficient by [52]:

$$
\overline{\boldsymbol{\alpha}}=\overline{\boldsymbol{C}}^{-1}: \boldsymbol{\beta}
$$


where

$$
\boldsymbol{\beta}=\frac{1}{|\Omega|} \int_{\Omega} \boldsymbol{C}: \boldsymbol{\alpha} \mathrm{d} \Omega
$$

The above equations will provide the average stress distribution in the stack, using the average stiffness distribution, average thermal expansion coefficient, etc. The full stiffness tensor can be achieved by a numerical sub-model of the actual geometry of the repeating element, see e.g. [49].

However, to give a good understanding of the procedure, we have in this work provided the analytical approximations for the in-plane stiffness and in-plane averaged thermal expansion coefficient. The reason for using this analytical approximation is that the stresses in the cells will be well represented by this approximation, as they are primarily determined by temperature and thermal strain variation across the cell plane. The geometry considered here is the same as for the other physics, although we make the approximation that the out-of-plane stiffness is the same as the in-plane stiffness (for simplicity). For a real stack, numerical homogenization can be used with advantage.

To predict failure, e.g., cracking of the electrolyte, the local stress distribution in the electrolyte is needed. The sub-model used to derive the average mechanical properties in Eqs. (38) and (39) can also be used to retrieve the local mechanical response. This is done by imposing the obtained effective (global) quantities from the homogenized modeling as boundary conditions on the repeating unit and calculate the local conditions in the sub-model. This is basically a multiscale model.

The analytical sub-model presented as follows can thus be used to obtain the local stresses in any of the cell layers based on the average strain calculated in the homogenized model. This will be explained in detail below.

A set of parameters for each of the two isotropic homogenous media in the model are used, i.e., a set for the active volume and a set for the surrounding sealing volume. 
For an isotropic media, the thermal expansion coefficient tensor $\overline{\boldsymbol{\alpha}}$ becomes a scalar $\bar{\alpha}$ and Eq. (36) simplifies considerably to:

$$
\bar{\sigma}_{i j}=\frac{\bar{E}}{(1+\bar{\nu})}\left[\bar{\epsilon}_{i j}+\frac{\bar{\nu}}{(1-2 \bar{\nu})} \bar{\epsilon}_{k k} \delta_{i j}-\frac{1+\bar{\nu}}{(1-2 \bar{\nu})} \bar{\epsilon}_{T} \delta_{i j}\right]
$$

where $\bar{E}$ is the volume averaged Youngs modulus.

$\bar{E}$ and $\bar{\alpha}$ are calculated based on the classical laminate theory [53-55]. This provides the average parameters for the in-plane stiffness and thermal expansion coefficient.

In the $i$ th layer, the constitutive law for linear elasticity is written as:

$$
\sigma=\frac{E_{i}}{1+\nu_{i}}\left(\epsilon-\epsilon_{T}\right)
$$

where $\sigma, \epsilon$ and $\epsilon_{T}$ are the local stress, total strain and thermal strain in the $i$ th layer. The total strain is usually varying across the thickness of the multi-layer according to:

$$
\epsilon=\epsilon_{0}+\kappa z
$$

where $\epsilon_{0}$ is the midplane strain, $\kappa$ is the curvature, and $z$ the coordinate of the layer thickness. For the stiffness averaging the cell layers are assumed to be constrained flat and contributions from curvature can be neglected $(\kappa=0)$.

The normal force is then calculated by the integration of stresses over all layers:

$$
N=\sum_{i=1}^{n} \int_{z_{i-1}}^{z_{i}} \sigma \mathrm{d} z=\sum_{i=1}^{n} \int_{z_{i-1}}^{z_{i}} \frac{E_{i}}{1+\nu_{i}}\left(\epsilon^{0}-\epsilon_{T}\right) \mathrm{d} z
$$


Using Eqs. (43) and (44) can be simplified to:

$$
N=A \epsilon-N_{T}
$$

where $A$ is defined as extensional stiffness:

$$
A=\sum_{i=1}^{n} \frac{E_{i}}{1+\nu_{i}}\left(z_{i}-z_{i-1}\right)
$$

and $N_{T}$ as:

$$
N_{T}=\sum_{i=1}^{n} \frac{E_{i}}{1+\nu_{i}} \Delta T \alpha_{i}\left(z_{i}-z_{i-1}\right)
$$

Comparing Eqs. (36) and (45) to (47) then, the in-plane average stress, Young's modulus and thermal expansion coefficient can be identified as:

$$
\begin{gathered}
\bar{\sigma}=\frac{N}{\Delta \mathrm{z}_{\mathrm{RE}}} \\
\bar{E}=\frac{A}{\Delta \mathrm{z}_{\mathrm{RE}}} \\
\bar{\alpha}=\frac{N_{T}}{A}
\end{gathered}
$$

where $\Delta z_{\mathrm{RE}}$ is the effective total height of the repeating unit.

The average linear thermal expansion, $\bar{\alpha}$, can thus be obtained with the following expression: 


$$
\bar{\alpha}=\frac{N_{T}}{A}=\frac{1}{A} \sum_{i=1}^{n} \frac{E_{i}}{1+\nu_{i}} \alpha_{i}\left(z_{i}-z_{i-1}\right)
$$

These stiffness and thermal expansion parameters are used in the calculation of the average stresses.

As mentioned, the stresses in the individual layers can be obtained by using the submodel, which in this case is an analytical expression. To do so, the strain in the specific layer is first identified to be equal to that of the average strain, as all layers move together. Consequently, the stress in a particular layer, e.g. the electrolyte, is calculated by subtracting the thermal strain and multiplying with the Youngs modulus of the particular layer (e.g. the electrolyte), Eq. (42).

Other more complex mechanical problems can also be handled with the homogenization approach, e.g., creep $[49,50]$. The following works will go into further details about the general numerical volume averaging and determination of local fractures in the homogenization modeling framework [56].

\section{Model results and simulation times}

In this section, various output results from the above described model framework are shown. These are stack temperature profiles, current density distributions and resulting stress variation under galvanostatic conditions and the effect of the gases' inlet temperature on the fuel utilization for electrolysis mode. Furthermore, calculation times for stacks comprised of different number of cells are reported to show the low computational cost using the homogenization approach. 


\subsection{Boundary conditions and assumptions}

The different boundary conditions for the different transport phenomena considered in the examples are presented in Table 2 . The boundaries where these conditions apply are shown in Fig. 3a). Boundaries 1 and 2 correspond to the side surfaces of the active stack volume, which are perpendicular planes to the y-direction (perpendicular to the flow direction). Boundary 1 is the inlet of the stack while boundary 2 is the outlet. Boundaries 3 and 4 correspond to the top and bottom surfaces of the stack.

For all the calculations performed in this work, the fuel/feedstock consists of a binary gas mixture of hydrogen and steam: $50 \% \mathrm{H}_{2}-50 \% \mathrm{H}_{2} \mathrm{O}$, in volume at the inlet. Atmospheric air is used at the air side. Some variables like the gases' inlet temperatures or the stack operating current are varied in the different calculations performed. The stack operates at atmospheric pressure (absolute pressure).
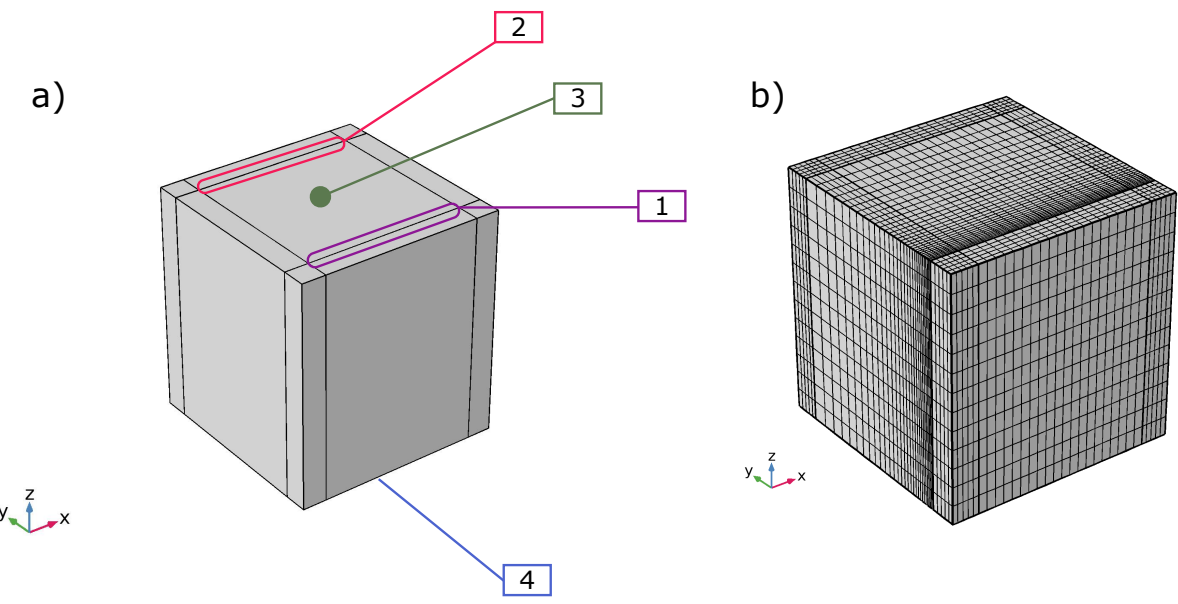

Figure 3: a) Locations of the stack's boundary conditions as specified in Table 2 and b) Mesh used in the simulations.

Regarding charge transport, unless as specified in Table 2, all the surfaces are electrically insulated. For the mechanical stresses, three vertices from the bottom surface of the stack, i.e., boundary 4 in Fig. 3, are constrained to prevent rigid body motion. Note that the stack operates in co-flow configuration. 
Table 2: Boundary conditions.

\begin{tabular}{lcccl}
\hline Variable & Value & Unit & Boundary $^{a}$ & Description \\
\hline$\dot{\mathrm{m}}_{\text {fuel }}$ & 180 & $\mathrm{~L} \mathrm{~min}^{-1}$ & 1 & Fuel mass flow rate at standard conditions \\
$\dot{\mathrm{m}}_{\text {air }}$ & 830 & $\mathrm{~L} \mathrm{~min}^{-1}$ & 1 & Air mass flow rate at standard conditions \\
$p_{\text {fuel }}$ & 0 & $\mathrm{~atm}$ & 2 & Relative pressure of the fuel stream at the outlet \\
$p_{\text {air }}$ & 0 & $\mathrm{~atm}$ & 2 & Relative pressure of the air stream at the outlet \\
$Y_{\mathrm{H}_{2} \mathrm{O}}$ & 0.5 & - & 1 & Inlet steam molar fraction \\
$Y_{\mathrm{O}_{2}}$ & 0.21 & - & 1 & Inlet oxygen molar fraction \\
$Y_{\mathrm{H}_{2} \mathrm{O}}$ & $-\boldsymbol{n} \cdot \mathbf{N}_{\mathrm{H}_{2} \mathrm{O}}=0$ & - & 2 & Zero gradient at the outlet \\
$Y_{\mathrm{O}_{2}}$ & $-\boldsymbol{n} \cdot \mathbf{N}_{\mathrm{O}_{2}}=0$ & - & 2 & Zero gradient at the outlet \\
$\mathrm{T}_{\text {fuel }}$ & 650 & ${ }^{\circ} \mathrm{C}$ & 1 & Inlet fuel temperature \\
$\mathrm{T}_{\text {air }}$ & 650 & ${ }^{\circ} \mathrm{C}$ & 1 & Inlet air temperature \\
$\mathrm{T}_{\text {fuel }}$ & $-\boldsymbol{n} \cdot \mathbf{q}_{\text {fuel }}=0$ & - & 2 & Zero gradient at the fuel outlet \\
$\mathrm{T}_{\text {air }}$ & $-\boldsymbol{n} \cdot \mathbf{q}_{\text {air }}=0$ & - & 2 & Zero gradient at the air outlet \\
$I_{\text {stack }}$ & A & A & 3 & Operating current of the stack \\
$V_{\text {ground }}$ & 0 & $\mathrm{~V}$ & 4 & Ground voltage \\
\hline
\end{tabular}

${ }^{a}$ see Fig. 3 a)

Furthermore, a heat flux boundary condition is implemented on the outer surfaces of the stack to account for the heat dissipation through an insulating material of $5 \mathrm{~cm}$ thickness to the surroundings, Eq. (50). Radiation at such high operating temperatures through the insulation material might have some effect on the heat transfer, but this has not been considered here for simplicity. This can of course be included, please refere to e.g. [57].

$$
q_{\text {ins }}=\frac{k_{\text {ins }}}{t_{\text {ins }}}\left(T_{\text {solids }}-T_{\text {surr }}\right)
$$

where $k_{\text {ins }}$ and $t_{\text {ins }}$ are the thermal conductivity and thickness of the insulation material, 
respectively, and $T_{\text {surr }}$ is the temperature of the surroundings. All operating and material parameters used in the simulations are presented in Table 3. All parameters related to the gases used are defined in Appendix A in [9]. 
Table 3: Operating and material parameters.

\begin{tabular}{|c|c|c|c|c|}
\hline Variable & Value & Unit & Description & Ref. \\
\hline$p_{\text {tot }}$ & 1 & atm & Absolute pressure & \\
\hline $\mathrm{T}_{\text {surr }}$ & 20 & ${ }^{\circ} \mathrm{C}$ & Temperature of the surroundings & \\
\hline$k_{\text {steel }}$ & 23 & $\mathrm{~W} \mathrm{~m}{ }^{-1} \mathrm{~K}^{-1}$ & Steel thermal conductivity & {$[58]$} \\
\hline$k_{\mathrm{Ni}, \mathrm{f}}$ & 5.89 & $\mathrm{~W} \mathrm{~m}^{-1} \mathrm{~K}^{-1}$ & Ni foam thermal conductivity & $b$ \\
\hline$k_{\mathrm{Cu}, \mathrm{f}}$ & 0.13 & $\mathrm{~W} \mathrm{~m}{ }^{-1} \mathrm{~K}^{-1}$ & $\mathrm{Cu}_{1+x} \mathrm{Mn}_{2-x} \mathrm{O}_{4}$ foam thermal conductivity & $b$ \\
\hline$k_{\text {cell }}$ & 2 & $\mathrm{~W} \mathrm{~m}^{-1} \mathrm{~K}^{-1}$ & Cell thermal conductivity & [59] \\
\hline$t_{\text {ins }}$ & 5 & $\mathrm{~cm}$ & Insulation material thickness & \\
\hline$k_{\text {ins }}$ & 0.04 & $\mathrm{~W} \mathrm{~m}{ }^{-1} \mathrm{~K}^{-1}$ & Insulation material thermal conductivity & [60] \\
\hline$\gamma_{x}, \gamma_{y}$ & $0.3 / \rho_{\text {crofer }}{ }^{a}$ & $\mathrm{~S} \mathrm{~cm}^{-1}$ & Volume averaged stack electric conductivity & [58] \\
\hline$E_{\text {steel }}$ & 86 & $\mathrm{GPa}$ & Steel Young's modulus & [61] \\
\hline$\nu_{\text {steel }}$ & 0.30 & - & Steel Poissons ratio & $c$ \\
\hline$E_{\mathrm{Ni}, \mathrm{f}}$ & 0.07 & $\mathrm{GPa}$ & Ni foam Young's modulus & $b$ \\
\hline$\nu_{\mathrm{Ni}, \mathrm{f}}$ & 0.2 & - & Ni foam Poissons ratio & $d$ \\
\hline$E_{\mathrm{Cu}, \mathrm{f}}$ & 4.84 & GPa & $\mathrm{Cu}_{1+x} \mathrm{Mn}_{2-x} \mathrm{O}_{4}$ foam Young's modulus & $b$ \\
\hline$\nu_{\mathrm{Cu}, \mathrm{f}}$ & 0.2 & - & $\mathrm{Cu}$ foam Poissons ratio & $d$ \\
\hline$E_{\mathrm{fe}}$ & 36.3 & GPa & Fuel electrode support Young's modulus & {$[62]$} \\
\hline$\nu_{\mathrm{fe}}$ & 0.30 & - & Fuel electrode support Poissons ratio & [63] \\
\hline$\alpha_{\text {steel }}$ & $11.9 \cdot 10^{-6}$ & $\mathrm{~K}^{-1}$ & Steel thermal expansion coefficient & {$[58]$} \\
\hline$\alpha_{\mathrm{Ni}, \mathrm{f}}$ & $17 \cdot 10^{-6}$ & $\mathrm{~K}^{-1}$ & $\mathrm{Ni}$ foam thermal expansion coefficient & {$[64]$} \\
\hline$\alpha_{\mathrm{Cu}, \mathrm{f}}$ & $13.9 \cdot 10^{-6}$ & $\mathrm{~K}^{-1}$ & $\mathrm{Cu}_{1+x} \mathrm{Mn}_{2-x} \mathrm{O}_{4}$ foam thermal expansion coefficient & [65] \\
\hline$\alpha_{\mathrm{fe}}$ & $12.3 \cdot 10^{-6}$ & $\mathrm{~K}^{-1}$ & Fuel electrode support thermal expansion coefficient & [66] \\
\hline$T_{r e f}$ & 800 & ${ }^{\circ} \mathrm{C}$ & Reference temperature for mechanical stresses & \\
\hline
\end{tabular}


Unless specified otherwise, calculations are performed using the inlet and boundary conditions specified in Table 2 for a 100 cell stack operating in co-flow configuration. Due to the high operating temperatures in SOC devices, the gases are treated as ideal gases. Under the specified operating conditions stated in Table 2, the Reynolds number for the air side are in the 125-146 range and for the fuel side in the 25-32 range. These Reynolds numbers clearly reflect a laminar flow regime with a negligible entry length (under $5 \%$ of the total length), giving validity to the fully developed flow assumption.

For the mechanical stresses, the reference temperature, $T_{\text {ref }}$ is assumed to be $800{ }^{\circ} \mathrm{C}$ as we are assuming that the reduction of the stack is conducted at this temperature. The reduction process induces fast creep in the cell [68], which is assumed to release all stresses at the point of reduction.

Mesh

One of the main reasons for applying the homogenization approach is the possibility for drastically decreasing the number of finite elements and thus, decrease the computational time and cost, compared to the required mesh for a stack model with all the details explicitly represented. In this work, for a 100 cell stack, 13 elements are used in the height direction resulting in a mesh of 15600 finite elements, see Fig. 3 b). The results with this amount of elements have been confirmed to vary insignificantly $(<1$ $\%$ ) if the mesh density is increased. A coarser mesh would also be reasonable for many simulations, in this paper the mesh density is however kept constant.

The density of the mesh is thus not determined by the number of cells in the stack or the number geometric features of the interconnect, but rather by the gradients of the independent variables solved for. The steeper the gradients the denser a mesh is needed to correctly capture the correct variation of the variable (inherent for the finite element method). For instance, as seen in Fig. 3, the mesh density is high at the flow inlet in the in $y$-direction in the current model in order to describe the high thermal gradients 
in this region.

\subsection{Model behavior at the base case}

An example of the many output parameters from the stack model is shown in Fig. 4 for a 100 cell stack operating at $60 \mathrm{~A}$ and with a gas inlet temperature of $650{ }^{\circ} \mathrm{C}$. This corresponds to fuel cell operation, where the stack is heated both by the electrochemical reactions and the joule heating.

The resulting temperature variation is shown in Fig. 4 a). It is seen that the primary temperature variation is in the flow direction as the gases are heated passing through the stack, due to the Joule heating and reaction heating (exothermic reaction). The curvature of the thermal profile in the cell plane is due to conduction in the solids, where heat is transported from the warmer center of the stack to the colder insulated perimeter. The thermal profile is also influenced by a high thermal conductivity in the sealing region (higher density than the active region). The temperature variation along the height of the stack ( $z$-direction) is also due to the heat transport by conduction through the insulation material. The majority of the heat transported from the stack is by convection $(2312 \mathrm{~W})$, as compared to that by conduction through the insulation (64 $\mathrm{W})$. This is generated by $894 \mathrm{~W}$ of electrical heating and $1482 \mathrm{~W}$ of reaction heat.

The current density variation in Fig. 4 b) reflects mainly the depletion of fuel. Therefore, the primary variation of current density is along the flow direction. There is also a small variation perpendicular to flow direction (both in the cell plane and along the height

of the stack), which is primarily caused by variation in temperature, as the variation of species is more or less constant in those directions, see Fig. 4 c).

With the current, the hydrogen is gradually consumed through the stack, which is illustrated with the variation of the molar fraction in Fig. 4 c). Again, the dominant variation is in the flow direction. The minor variation in current density is found to 
be perpendicular to the flow direction, and has little influence on the molar fraction distribution.

The relatively narrow channels used in the current stack design provides a high pressure drop across the stack as shown in Fig. 4 d). The pressure only varies in the flow direction, as we assume the inflow to be controlled by a uniform pressure distribution over the height of the stack. In real stacks, this depends on the flow volume in the manifolds, and some variation can be expected from the base-plate to the top cells. This can be simulated, but has not been included in the current version of the model. It is important to control the overpressure on the air side as too high overpressures can break apart stack components. At the same time, there has to be enough air flowing through the stack to ensure that the temperature gradients are not too large so that the stack is under compression and thermal cracks are avoided.

The temperature distribution over the stack gives rise to some average thermal stresses as shown in Fig. 4 e). The stress component shown in Fig. 4 e) is the so-called first principal stress, as this is the largest tensile stress found in any coordinate system, and thus the most critical one for failure of the ceramic components. The stresses are generated primarily around the gases' outlets, where the highest temperatures are found, especially in the center of the flow outlet. The larger thermal expansions here generate tensile stresses along the colder insulated perimeter. It is also important to notice the significant variation of the stresses along the height of the stack, which highlights the limitation of using a repeating unit to represent the entire stack. In particular, the outermost cells experience a large variation in stress as compared to the central cells.

The stress variation presented in Fig. 4 e) is, as stated, the average stress distribution calculated with the average stiffness and thermal expansion coefficient of all the stack components. However, to investigate for failure, these stresses are perhaps less meaningful and the stresses in the individual component or in the interface between the components are needed. Using the analytical model presented in Section 2.3, the stresses in the different layers of the stack can be calculated. Using this approach, 
the first principal stress variation in the electrolyte has been calculated and shown in Fig. 4 f). The variation is seen to be similar to that of the average first principal stress variation. The stresses are however all negative, which is due to the residual stresses generated due to the lower thermal expansion coefficient of the electrolyte compared to the other layers of the cell and the other stack components, together with a reference temperature of $800^{\circ} \mathrm{C}$.

a)

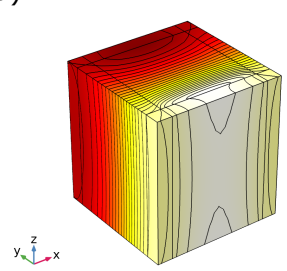

d)

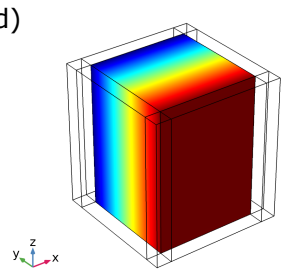

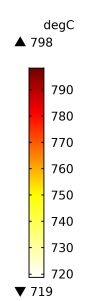

\ 256 mar

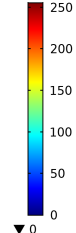

b)

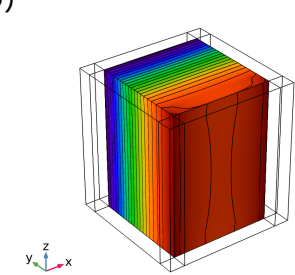

e)

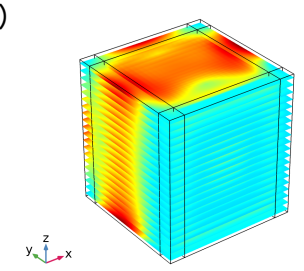

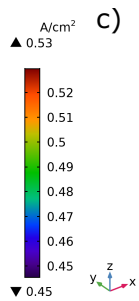

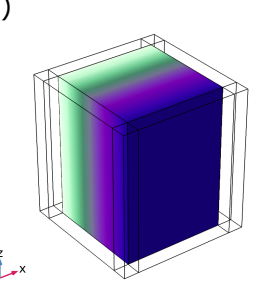

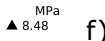

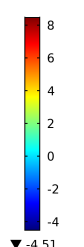

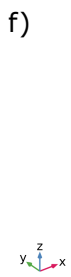

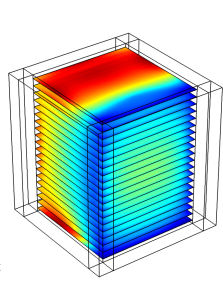

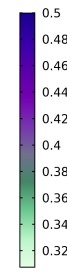

$\Delta{ }^{\text {MPa }}$

Figure 4: a) Stack temperature, b) Current density, c) Hydrogen molar fraction, d) Pressure drop on the air side, e)First principal stress in the stack and f) First principal stress in the electrolyte at $60 \mathrm{~A}$ and $650^{\circ} \mathrm{C}$ as the gases' inlet temperature for a 100 cell stack.

It is clear from this example that the model provides an output, which is physically meaningful given the stated operation conditions. This is natural as the method used is basically a mathematical abstraction of the first models presented by Achenbach and others [22-25].

\subsection{Fuel cell operation}

Three different stack operating currents corresponding to fuel cell mode and three other currents corresponding to electrolysis mode have been chosen to illustrate the output of the model in endo- and exothermic modes of operation. Current density 
distributions and the first principle stress profiles in the electrolyte, which is the most brittle component, have also been shown.

The different profiles under fuel cell mode are shown in Fig. 5. The currents chosen are 40, 60 and $80 \mathrm{~A}$. Note that all profiles present their own scale-bar.

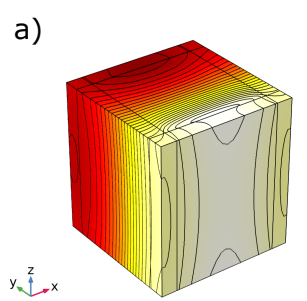

d)

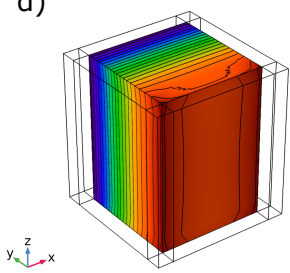

g)

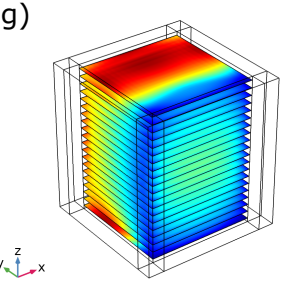

$\mathrm{I}=40 \mathrm{~A}$
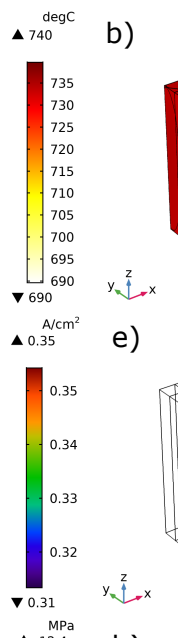

A. 12.4

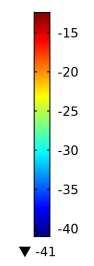

e)

h)
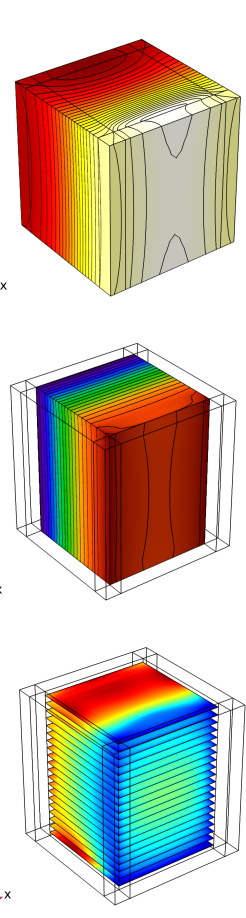

$\mathrm{I}=60 \mathrm{~A}$ c)

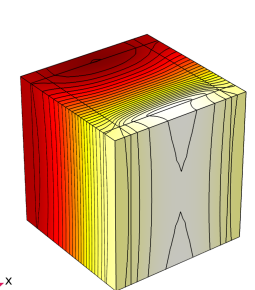

f)

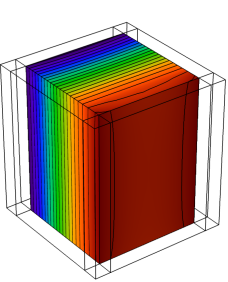

i)

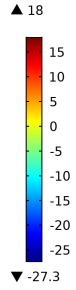

Zx

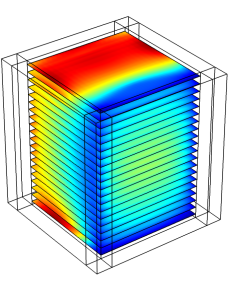

$\mathrm{I}=80 \mathrm{~A}$

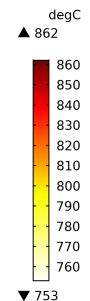

$\mathrm{A} / \mathrm{cm}^{2}$

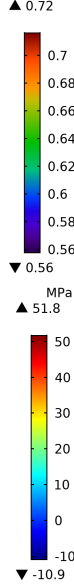

$\triangle 51.8$

Figure 5: Stack temperature: a) to c), Current density: d) to e) and First principal stress in the electrolyte: g) to i) profiles under fuel cell mode at $40 \mathrm{~A}, 60 \mathrm{~A}$ and $80 \mathrm{~A}$ for a 100 cell stack.

The temperature profiles, Fig. 5 a), b) and c), clearly show an exothermic behavior under fuel cell mode for the different operating voltages considered. With the choice of a constant air flow rate and inlet temperature, the temperature increases with increasing current.

The current density variation, Fig. 5 d), e) and f), reflects again the depletion of the fuel, and to a minor degree, the variation of temperature and with that, the ASR, which 
decreases with increasing temperature.

The first principal stress distributions in the electrolyte, Fig. 5, g), h) and i), vary in the cell plane but also significantly along the height of the stack. The high temperatures at $80 \mathrm{~A}$ result in tensile stresses in the electrolyte, as the reference temperature (800 ${ }^{\circ} \mathrm{C}$ ) is below the operating temperatures, and the thermal expansion coefficient of the electrolyte is lower than the remaining cell and stack components. Also, this is reflected with tensile stresses in the electrolyte, which for the high values shown would mean an increased probability for electrolyte fracture.

\subsection{Electrolysis operation}

Figure 6 presents the temperature, current density and principal stress profiles in the electrolyte for the electrolysis operation mode. As with the fuel cell mode, three different currents are chosen: $-50,-70$ and -90 A.

The stack temperature profiles under electrolysis mode obtained, Fig. 6 a), b) and c), also reproduce the expected thermal behavior according to thermodynamics. For -50 A, which corresponds to a voltage below the thermo-neutral voltage, $V_{\mathrm{tn}}$, the stack thermal behavior is endothermic; i.e., the heat consumed by the electrochemical reaction is larger than the heat released from ohmic losses. At $-70 \mathrm{~A}$, the stack temperature is almost constant as it is very close to the thermo-neutral voltage for a $\mathrm{H}_{2} / \mathrm{H}_{2} \mathrm{O}$ fuel mixture at approximately $750{ }^{\circ} \mathrm{C}$. Last current, $-90 \mathrm{~A}$, corresponds to an operating voltage above the thermo-neutral voltage, where the stack presents an exothermic behavior. Current density distributions, Fig. 6 d), e) and f), depend primarily again on the species

concentration. The principal stresses in the electrolyte profiles, Fig. $6 \mathrm{~g}$ ), h) and i), are all negative. Thus, no failures are to be expected. 

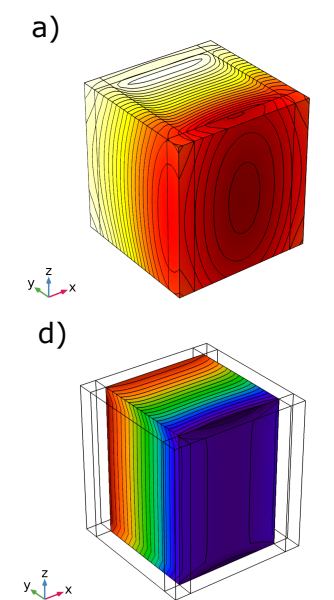

g)

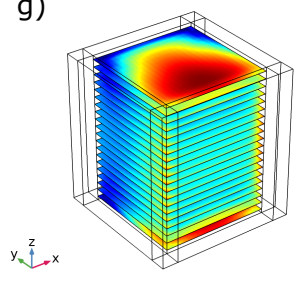

$I=-50 A$
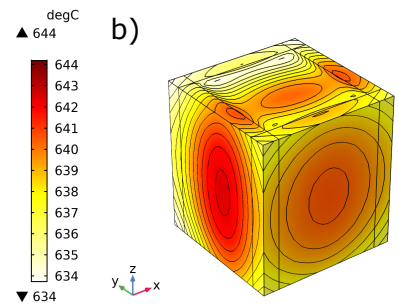

e)

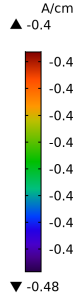

$\mathrm{MPa}$
$\mathbf{\triangle}-59.8$

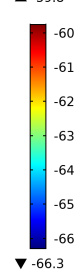

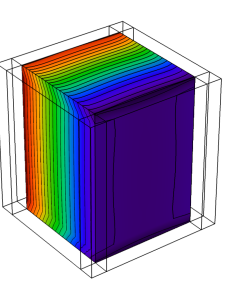

h)

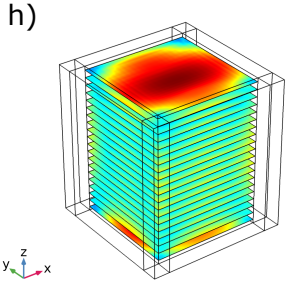

$I=-70 A$

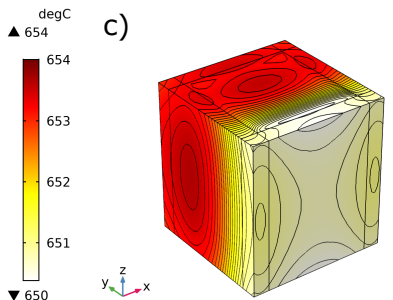

f)

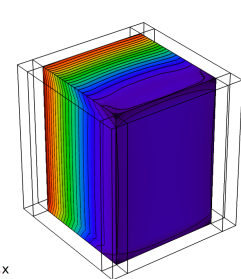

i)
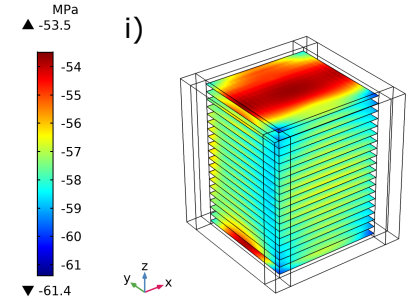

$I=-90 A$

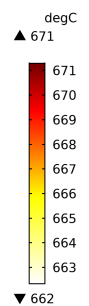

$\mathrm{A} \mathrm{cm}^{2}$
$\mathbf{A}-0.69$

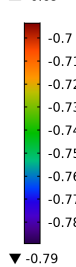

$\triangle{ }_{-4.2}^{M P a}$

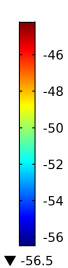

Figure 6: Stack temperature: a) to c), Current density: d) to e) and First principal stress in the electrolyte: g) to i) profiles under electrolysis mode at -50 A, -70 A and -90 A for a 100 cell stack.

\subsection{Effect of temperature and current variations}

Moreover, current density-voltage $(i-\mathrm{V})$ curves for the 100 cell stack with the gas flows and composition specified in Table 2 have been computed for different gas inlet temperatures. Both gases (fuel and air) have been set to the same inlet temperature. Temperatures range from 650 to $850{ }^{\circ} \mathrm{C}$. The $i$-V curves are shown in Fig. 7 a).

The $i$ - $\mathrm{V}$ curves dependency of temperature as shown in Fig. 7 a) is due to the temperature dependent Nernst potential and a temperature dependent ASR. 


\subsection{Fuel utilization}

The model has also been used to study the effect of temperature and current density (/stack voltage) on the fuel utilization for the electrolysis mode.

The fuel/feedstock utilization (FU) has been calculated at different operating voltages for the 100 cell stack. The gases' inlet temperatures have been varied between 650 and $850{ }^{\circ} \mathrm{C}$ while the gas flows, compositions and other boundary conditions are those specified in Table 2. The fuel utilization has been determined for a range of operating voltages that cover the electrolysis mode, see Fig. 7 b), and is given as function the steam molar fraction $\left(\mathrm{FU}[\%]=\left(\frac{Y_{\mathrm{H}_{2} \mathrm{O}, \text { in }}-Y_{\mathrm{H}_{2} \mathrm{O}, \text { out }}}{Y_{\mathrm{H}_{2} \mathrm{O}, \text { in }}}\right) 100\right)$.

Figure $7 \mathrm{~b}$ ) shows the fuel utilization as function of the stack operating voltage and gases inlet temperatures. Results can be related to the $i$-V curves in Fig. 7 a). For a specific voltage, higher current density is achieved at higher inlet gas temperature, and thus, more hydrogen is being produced or, in other words, a higher FU is achieved. For the conditions considered here, the highest FU values $(\sim 65 \%)$ are reached at $140 \mathrm{~V}$.

\subsection{Calculation times}

The main advantage the homogenization approach has is the high computational efficiency compared to a model with all the details of the stack explicitly represented. Calculation times for stacks with different number of cells have been reported for two computers: a laptop and a workstation. Clusters can be used to study different operating points in parallel, but as such, there is no need for clusters to perform the simulations, as the model is far less computationally demanding than a conventional model.

The calculation times reported correspond to a single run (one current value) for a stack considering all the physics described except for the mechanical stresses. These can be calculated once the temperature profiles are obtained. The laptop contains an Intel(R) 

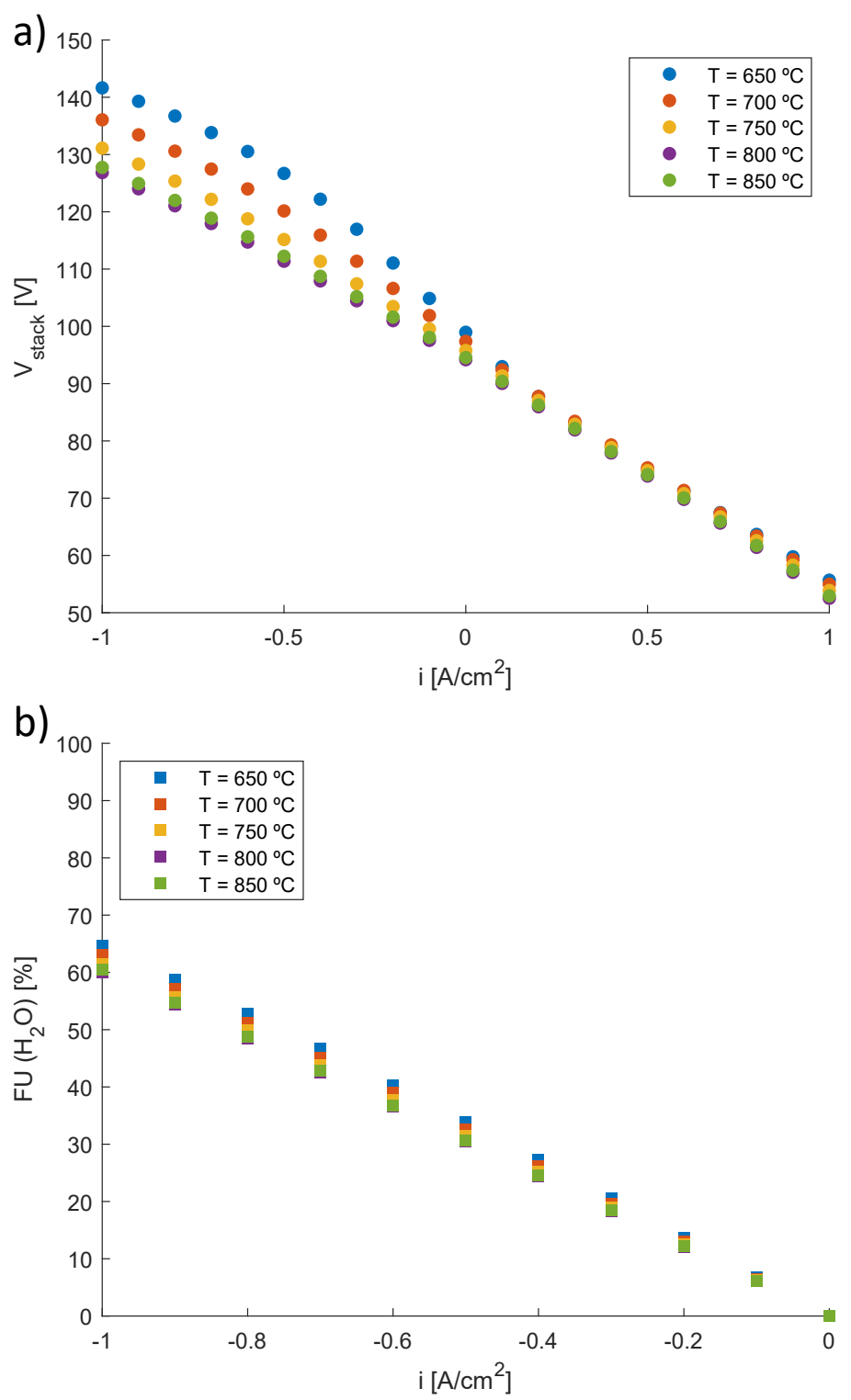

Figure 7: a) $\mathrm{i}$-V curves at different gas inlet temperatures for a $50 \% \mathrm{H}_{2}-50 \% \mathrm{H}_{2} \mathrm{O}$ fuel mixture in a 100 cell stack and $b$ ) Fuel utilization for the electrolysis mode as function of the gases inlet temperatures. 
Core(TM) i7-6600 CPU@ 2.60GHz 2.81 GHz processor and 24 GB installed RAM, while the workstation includes an Intel(R) Xeon(R) CPU E5-1650v4@3.60 GHz 3.60 GHz processor and 128 GB installed RAM. The times are shown in Fig. 8.

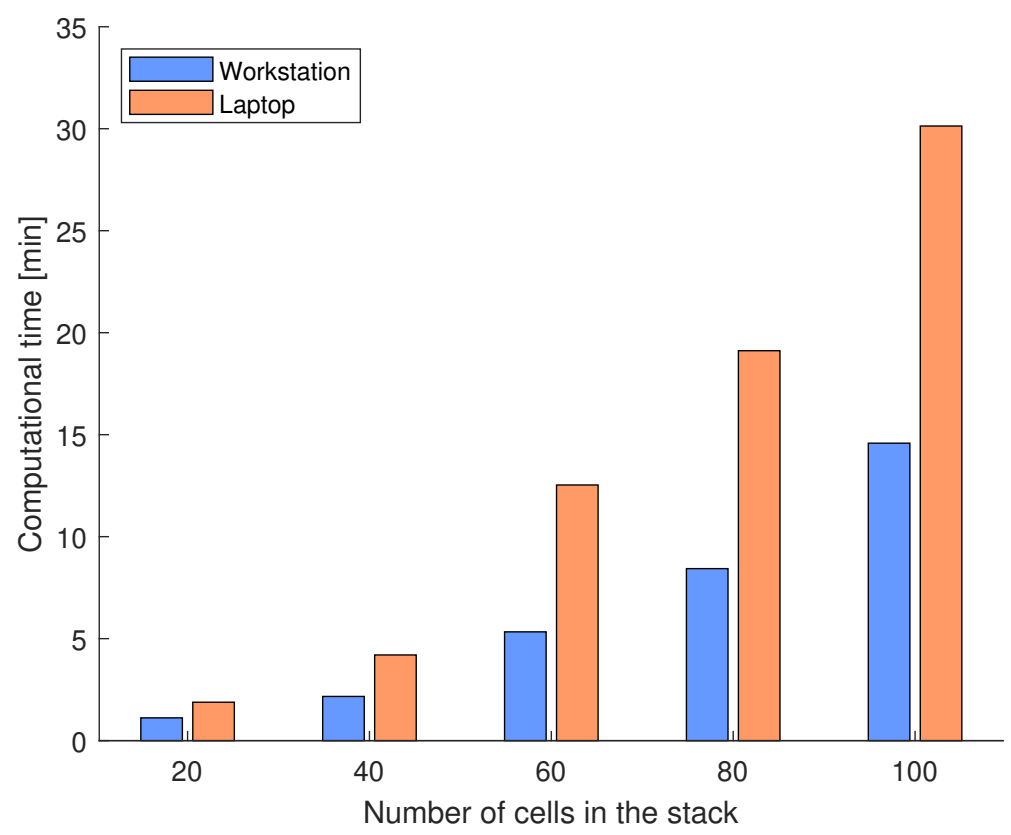

Figure 8: Computational times for a single run depending on the stack cell number and the computer used when the homogenization approach is used.

Figure 8 shows very attractive computational times for such a complex multiphysics model of an SOC stack, as compared to state of the art models with computational times of $40+$ hours for a 30 cell stack. These low computational times are a significant improvement which can be a very valuable tool for stack design and prototyping. These fast calculations allow retrieving thermal profiles, pressure drops across the stack, species and current distributions under different operating conditions or geometry modifications - for a high number of modes of operation, different stack designs, etc. 


\section{Outlook}

The purpose of this manuscript is to present the full-homogenization approach applied to an SOC stack and show that it can be a very valuable tool for fast prototyping of such devices. The current paper shows the basic homogenization concept and future works will address more realistic stack designs, utilize numerical models to retrieve the homogenized parameters and improve various sub-models such as mechanical stress concentrations, etc.

As explained, it is fully possible to consider more complex stack geometries, e.g., with more complex channel shapes without the loss of computational efficiency (simply a different effective permeability). By representing the pressure drop along the height of the stack from the inlet base plate and hereby, one describe possible mal-distribution of gas flow. Manifolds will also be represented in future model updates. This will be at the cost of some computational speed.

Better local description of the different physical sub-models are also possible within the existing framework. For example, the same cell model framework used for describing the local overpotentials (via the ASR) can also be used to describe degradation [17]. Combining this with a computational efficient time-dependent stack model would be extremely useful for describing the long-term behavior of an SOC stack to investigate if accelerating effects are present at some locations in the full stack. The current stack model framework should be extended, but as the time-dependent versions of all the conventional PDEs used in this SOC stack model framework are known, this seems feasible.

Although the basic concept of calculating the thermo-mechanical stresses are presented in this work, the current representation only accounts for the immediate mechanical response (the elastic), whereas the high temperature is known to result in plastic behavior of the various materials in the SOC stack, in particular time-dependent plasticity, i.e. 
creep [15, 49]. As shown in [49], this can be handled using homogenization as well. Local failures such as loss of contact between cell and interconnect and failure of the sealing area are critical failures in the SOC stacks. Our current research focuses on describing this using the homogenization approach, making it possible to investigate for local failures for the entire stack with no loss of computational efficiency.

\section{Conclusions}

In this work, an original modeling concept for modeling and simulating electrochemical devices such as a solid oxide cell stack is presented. The novelty of the modeling concept presented resides in using the so-called homogenization to implicitly account for geometric, kinematic and dynamic properties of an operating SOC stack, by representing it with a homogeneous anisotropic media. This produces the same overall response of the stack although the local conditions are not explicitly represented. The approach minimizes the computational cost such that simulation time is reduced two orders of magnitude when compared to those of conventional models, where geometric details are explicitly represented.

In this paper, the methodology for obtaining the properties of the homogeneous media representing the stack is shown. This is done on a simplified stack geometry, as most of the homogenization can therefore be made analytically, providing a greater understanding of the method. This method will also be applied on more complex stack geometries in future works, using numerical sub-models. Following physical phenomena have been described using homogenization; electrochemical reactions, transport of current, flow of gases, heat transfer in solids and gases, mass transport and diffusion, mechanical stresses and all the couplings between them.

To exemplify the output from the model, a number of different case studies have been simulated using a 100 cell stack. Thus fuel/feedstock utilization, pressure variation, 
current densities, temperature distribution, and mechanical stresses are shown for different inlet temperatures of the gases and stack voltages. The latter has been chosen such that electrolysis and fuel cell modes of operation are represented. To show the computational efficiency, the calculation time for SOC stacks with different number of cells on a workstation computer were presented, ranging from 1.2 to 14.5 minutes for a 20 and 100 cell stack, respectively.

Although, the model only represents the overall behavior of the stack, it is possible to describe local quantities using sub-models. This has been exemplified by calculating the local stress distribution in the electrolyte as a function of the average global stress. In a similar manner local quantities such as concentrations, overpotentials or other quantities can be represented. In some cases this can be done in terms of closed-form expressions and maintaining a high computational efficiency, which is the focus of ongoing research.

\section{List of symbols}

A

$a_{i}$

C

$c$

$c_{p}$

$D_{h}$

d

E

$\bar{E}$

F

$f_{D}$

G
Convective heat transfer area, $\left[\mathrm{m}^{2}\right]$ or extensional stiffness, $\left[\mathrm{N} \mathrm{m}^{-1}\right]$

Chemical activity of species $i$, dimensionless

Stiffness tensor, $[\mathrm{GPa}]$

Molar density, $\left[\mathrm{mol} \mathrm{m}^{-3}\right]$

Specific heat at constant pressure, $\left[\mathrm{J} \mathrm{kg}^{-1} \mathrm{~K}^{-1}\right]$

Hydraulic diameter, [m]

Depth, $[\mathrm{mm}]$ or $[\mathrm{cm}]$

Cell open circuit voltage, $[\mathrm{V}]$

Volume averaged Young modulus, [GPa]

Faraday constant, $\left[\mathrm{C} \mathrm{mol}^{-1}\right]$

Darcy's friction factor, dimensionless

Gibbs free energy, $\left[\mathrm{J} \mathrm{mol}^{-1}\right]$ 


\begin{tabular}{|c|c|}
\hline$g_{c}$ & Shape correction factor, dimensionless \\
\hline$g_{a}$ & Minimum aspect ratio between channel height and width, dimensionless \\
\hline$h$ & Convective heat transfer coefficient \\
\hline$I$ & Current, $[\mathrm{A}]$ \\
\hline $\mathbf{i}$ & Current density flux, $\left[\mathrm{A} \mathrm{m}^{-2}\right]$ \\
\hline$i$ & Current density, $\left[\mathrm{A} \mathrm{m}^{-2}\right]$ \\
\hline$k$ & Thermal conductivity, $\left[\mathrm{W} \mathrm{m}^{-1} \mathrm{~K}^{-1}\right]$ \\
\hline $\mathbf{N}$ & Molar flux of gas species, $\left[\mathrm{mol} \mathrm{m}^{-2} \mathrm{~s}^{-1}\right]$ \\
\hline$N$ & Normal force, $[\mathrm{N}]$ \\
\hline $\mathrm{N}_{\text {cells }}$ & Number of cells, dimensionless \\
\hline$n$ & Normal vector, dimensionless \\
\hline$n$ & Number of species $i$ in the gas mixture, dimensionless \\
\hline$n_{e}$ & Number of electrons transferred per reaction, dimensionless \\
\hline $\mathrm{Nu}$ & Nusselt number, dimensionless \\
\hline$P$ & Pressure, $[\mathrm{Pa}]$ or $[\mathrm{atm}]$ \\
\hline$p_{i}$ & Partial pressure of species $i,[\mathrm{~atm}]$ \\
\hline$p^{\ominus}$ & Standard pressure, $[\mathrm{atm}]$ \\
\hline$p$ & Parameter, different units \\
\hline$q$ & Heat flux, $\left[\mathrm{W} \mathrm{m}^{-3}\right]$ \\
\hline$q$ & Heat flux boundary source, $\left[\mathrm{W} \mathrm{m}^{-2}\right]$ \\
\hline$R$ & Ideal gas constant, $\left[\mathrm{J} \mathrm{mol}^{-1} \mathrm{~K}^{-1}\right]$ \\
\hline$R_{j}$ & Equivalent thermal resistance in the different axes, $\left[\mathrm{K} \mathrm{W}^{-1}\right]$ \\
\hline $\operatorname{Re}$ & Reynolds number, dimensionless \\
\hline$S$ & Entropy, $\left[\mathrm{J} \mathrm{mol}^{-1} \mathrm{~K}^{-1}\right]$ \\
\hline$S_{m}$ & Source term for the mass conservation equation, $\left[\mathrm{mol} \mathrm{m}^{-3} \mathrm{~s}^{-1}\right]$ \\
\hline$S_{T}$ & Source term for the energy conservation equation, $\left[\mathrm{J} \mathrm{m}^{-3} \mathrm{~s}^{-1}\right]$ \\
\hline$T$ & Temperature, $[\mathrm{K}]$ \\
\hline$t$ & Thickness, $[\mu \mathrm{m}]$ or $[\mathrm{mm}]$ \\
\hline $\mathbf{U}$ & Velocity vector, $\left[\mathrm{m} \mathrm{s}^{-1}\right]$ \\
\hline$V$ & Voltage, $[\mathrm{V}]$ \\
\hline
\end{tabular}




$\begin{array}{ll}V_{\mathrm{tn}} & \text { Thermo-neutral voltage, }[\mathrm{V}] \\ \mathrm{w} & \text { Width, }[\mathrm{mm}] \text { or }[\mathrm{cm}] \\ \mathrm{Y}_{i} & \text { Molar fraction of species } i \text {, dimensionless }\end{array}$

\section{Greek letters}

$\begin{array}{ll}\alpha & \text { Linear thermal expansion tensor, }\left[\mathrm{K}^{-1}\right] \\ \Delta z & \text { Height, }[\mu \mathrm{m}] \text { or }[\mathrm{mm}] \\ \varepsilon & \text { Porosity of the electrodes, dimensionless } \\ \epsilon & \text { Total strain, }[\mathrm{GPa}] \text { or dimensionless } \\ \epsilon_{T} & \text { Thermal strain, }[\mathrm{GPa}] \text { or dimensionless } \\ \eta & \text { Overpotential, }[\mathrm{V}] \\ \kappa & \text { Permeability of the porous medium, }\left[\mathrm{m}^{2}\right] \text { or curvature, }\left[\mathrm{m}^{-1}\right] \\ \gamma & \text { Electric conductivity, }\left[\mathrm{S} \mathrm{cm}^{-1}\right] \\ \mu & \text { Chemical potential, }\left[\mathrm{J} \mathrm{mol}^{-1}\right] \\ \nu & \text { Poisson's ratio, dimensionless } \\ \Omega & \text { Volume, }\left[\mathrm{m}^{3}\right] \\ \pi & \text { Electromotive or Fermi potential, }[\mathrm{V}] \\ \rho & \text { Density, }\left[\mathrm{kg} \mathrm{m}{ }^{-3}\right] \text { or electrical resistivity, }[\Omega \mathrm{cm}] \\ \sigma & \text { Stress, }[\mathrm{GPa}]\end{array}$

Chemical species \& compounds

$\begin{array}{ll}\mathrm{Cu}_{1+x} \mathrm{Mn}_{2-x} \mathrm{O}_{4} & \text { Copper-Manganese spinel } \\ \mathrm{H}_{2} & \text { Hydrogen } \\ \mathrm{H}_{2} \mathrm{O} & \text { Water (steam) } \\ \mathrm{N}_{2} & \text { Nitrogen } \\ \mathrm{Ni} & \text { Nickel } \\ \mathrm{O}_{2} & \text { Oxygen }\end{array}$


Abbreviations

$\begin{array}{ll}\text { 1D/2D/3D } & \text { One, two or three dimensional } \\ \text { ASR } & \text { Area specific resistance } \\ \text { CFD } & \text { Computational fluid dynamics } \\ \text { DGM } & \text { Dusty gas model } \\ \text { FEM } & \text { Finite element method } \\ \text { RE } & \text { Repeating element } \\ \text { SoA } & \text { State of the art } \\ \text { SOC } & \text { Solid oxide electrochemical cell } \\ \text { SOEC } & \text { Solid oxide electrolysis cell } \\ \text { SOFC } & \text { Solid oxide fuel cell }\end{array}$

\section{References}

\section{References}

[1] J. Laurencin, D. Kane, G. Delette, J. Deseure, F. Lefebvre-Joud, Modelling of solid oxide steam electrolyser: Impact of the operating conditions on hydrogen production, Journal of Power Sources 196 (4) (2011) 2080-2093.

[2] X. Jin, X. Xue, Computational fluid dynamics analysis of solid oxide electrolysis cells with delaminations, International Journal of Hydrogen Energy 35 (14) (2010) $7321-7328$.

[3] M. Ni, 2D thermal modeling of a solid oxide electrolyzer cell (SOEC) for syngas production by $\mathrm{H} 2 \mathrm{O} / \mathrm{CO} 2$ co-electrolysis, International Journal of Hydrogen Energy 37 (8) (2012) 6389-6399. 
[4] G. Hawkes, J. O’Brien, C. Stoots, B. Hawkes, 3D CFD model of a multi-cell hightemperature electrolysis stack, International Journal of Hydrogen Energy 34 (9) (2009) 4189-4197.

[5] A. Enrico, M. Cannarozzo, P. Costamagna, Modeling analysis of Bi-layer Ni$(\mathrm{ZrO} 2) \mathrm{x}(\mathrm{Y} 2 \mathrm{O} 3) 1-\mathrm{x}$ anodes for anode-supported intermediate temperature-solid oxide fuel cells, Energies 7 (9) (2014) 5647-5674.

[6] A. Nakajo, Z. Wuillemin, P. Metzger, S. Diethelm, G. Schiller, J. Van herle, D. Favrat, Electrochemical Model of Solid Oxide Fuel Cell for Simulation at the Stack Scale I. Calibration Procedure on Experimental Data, Journal of The Electrochemical Society 158 (9) (2011) B1083.

[7] P. Pianko-Oprych, T. Zinko, Z. Jaworski, Computational fluid dynamics calculation of a planar solid oxide fuel cell design running on syngas, Chemical and Process Engineering - Inzynieria Chemiczna i Procesowa 38 (4) (2017) 513-521.

[8] M. Navasa, C. Graves, C. Chatzichristodoulou, T. L. Skafte, B. Sundén, H. L. Frandsen, A three dimensional multiphysics model of a solid oxide electrochemical cell: A tool for understanding degradation, International Journal of Hydrogen Energy 43 (27) (2018) 11913 - 11931.

[9] M. Navasa, H. L. Frandsen, T. L. Skafte, B. Sundén, C. Graves, Localized carbon deposition in solid oxide electrolysis cells studied by multiphysics modeling, Journal of Power Sources 394 (2018) 102 - 113.

[10] A. Li, C. Song, Z. Lin, A multiphysics fully coupled modeling tool for the design and operation analysis of planar solid oxide fuel cell stacks, Applied Energy 190 (2017) $1234-1244$.

[11] R. Nishida, S. Beale, J. Pharoah, Comprehensive computational fluid dynamics model of solid oxide fuel cell stacks, International Journal of Hydrogen Energy 41 (45) (2016) $20592-20605$.

[12] R. Nishida, S. Beale, J. Pharoah, L. de Haart, L. Blum, Three-dimensional computational fluid dynamics modelling and experimental validation of the Jülich 
Mark-F solid oxide fuel cell stack, Journal of Power Sources 373 (2018) 203 210.

[13] A. Nakajo, P. Tanasini, S. Diethelm, J. Van herle, D. Favrat, Electrochemical Model of Solid Oxide Fuel Cell for Simulation at the Stack Scale II: Implementation of Degradation Processes, Journal of The Electrochemical Society 158 (9) (2011) B1102.

[14] A. Nakajo, J. Van Herle, D. Favrat, Sensitivity of stresses and failure mechanisms in SOFCs to the mechanical properties and geometry of the constitutive layers, Fuel Cells 11 (4) (2011) 537-552.

[15] F. Greco, H. L. Frandsen, A. Nakajo, M. F. Madsen, J. V. Herle, Modelling the impact of creep on the probability of failure of a solid oxide fuel cell stack, Journal of the European Ceramic Society 34 (11) (2014) 2695 - 2704.

[16] P. Pianko-Oprych, T. Zinko, Z. Jaworski, A Numerical Investigation of the Thermal Stresses of a Planar Solid Oxide Fuel Cell, Materials 9 (10).

[17] S. Dierickx, N. Russner, A. Weber, E. Ivers-Tiffée, A predictive degradation model for SOFC-cells and stacks, Proceedings of 13th European SOFC \& SOEC Forum 2018 (July) (2018) A1401-A1401.

[18] Z. He, H. Li, E. Birgersson, Reduced model for the planar solid oxide fuel cell, Computers \& Chemical Engineering 52 (2013) 155 - 167.

[19] M. Peksen, A coupled 3D thermofluidthermomechanical analysis of a planar type production scale SOFC stack, International Journal of Hydrogen Energy 36 (18) (2011) $11914-11928$.

[20] M. Peksen, A. Al-Masri, L. Blum, D. Stolten, 3D transient thermomechanical behaviour of a full scale SOFC short stack, International Journal of Hydrogen Energy 38 (10) (2013) 4099 - 4107.

[21] M. Peksen, 3D thermomechanical behaviour of solid oxide fuel cells operating in different environments, International Journal of Hydrogen Energy 38 (30) (2013) $13408-13418$. 
[22] E. Achenbach, Three-dimensional and time-dependent simulation of a planar solid oxide fuel cell stack, Journal of Power Sources 49 (1-3) (1994) 333-348.

[23] P. Hendriksen, Model studies of internal steam reforming in SOFC stacks, The Electrochemical Society, 1319-1328, 1997.

[24] J. Ferguson, J. Fiard, R. Herbin, Three-dimensional numerical simulation for various geometries of solid oxide fuel cells, Journal of Power Sources 58 (2) (1996) $109-122$.

[25] P. Costamagna, Modeling of Solid Oxide Heat Exchanger Integrated Stacks and Simulation at High Fuel Utilization, Journal of The Electrochemical Society 145 (11) (1998) 3995.

[26] S. B. Beale, S. V. Zhubrin, A distributed resistance analogy for solid oxide fuel cells, Numerical Heat Transfer, Part B: Fundamentals 47 (6) (2005) 573-591.

[27] A. Al-Masri, M. Peksen, L. Blum, D. Stolten, A 3D CFD model for predicting the temperature distribution in a full scale APU SOFC short stack under transient operating conditions, Applied Energy 135 (2014) 539 - 547.

[28] M. Kvesi, U. Reimer, D. Froning, L. Lüke, W. Lehnert, D. Stolten, 3D modeling of a $200 \mathrm{~cm} 2$ HT-PEFC short stack, International Journal of Hydrogen Energy 37 (3) (2012) 2430 - 2439, 2010 AIChE Annual Meeting Topical Conference on Hydrogen Production and Storage Special Issue.

[29] C. C. Mei, J.-L. Auriault, C.-O. Ng, Some Applications of the Homogenization Theory, Advances in Applied Mechanics 32 (1996) 277-348.

[30] A. Alù, First-principles homogenization theory for periodic metamaterials, Phys. Rev. B 84 (2011) 075153.

[31] T. Arbogast, J. Douglas, Jr., U. Hornung, Derivation of the Double Porosity Model of Single Phase Flow via Homogenization Theory, SIAM Journal on Mathematical Analysis 21 (4) (1990) 823-836. 
[32] B. Aoubiza, J. Crolet, A. Meunier, On the mechanical characterization of compact bone structure using the homogenization theory, Journal of Biomechanics 29 (12) (1996) 1539-1547.

[33] G. C. Glatzmaier, W. F. Ramirez, Use of volume averaging for the modeling of thermal properties of porous materials, Chemical Engineering Science 43 (12) (1988) $3157-3169$.

[34] J. Lux, A. Ahmadi, C. Gobbé, C. Delisée, Macroscopic thermal properties of real fibrous materials: Volume averaging method and 3D image analysis, International Journal of Heat and Mass Transfer 49 (11) (2006) 1958 - 1973.

[35] J. Chen, G. Zhang, B. Li, Molecular Dynamics Simulations for Computing Thermal Conductivity of Nanomaterials: Molecular Dynamics Simulations for Computing Thermal Conductivity of Nanomaterials, ISBN 978-981-4463-02-7, 1-57, doi:10.1201/b15658-2, 2015.

[36] S. Zhai, P. Zhang, Y. Xian, J. Zeng, B. Shi, Effective thermal conductivity of polymer composites: Theoretical models and simulation models, International Journal of Heat and Mass Transfer 117 (2018) 358 - 374.

[37] R. Nayak, D. P. Tarkes, A. Satapathy, A computational and experimental investigation on thermal conductivity of particle reinforced epoxy composites, Computational Materials Science 48 (3) (2010) 576 - 581.

[38] C. Kral, A. Haumer, M. Haigis, H. Lang, H. Kapeller, Comparison of a CFD Analysis and a Thermal Equivalent Circuit Model of a TEFC Induction Machine With Measurements, IEEE Transactions on Energy Conversion 24 (4) (2009) 809-818.

[39] P. K. Schelling, S. R. Phillpot, P. Keblinski, Comparison of atomic-level simulation methods for computing thermal conductivity, Phys. Rev. B 65 (2002) 144306.

[40] J. Burgos, V. P. Manno, K. Azar, Achieving accurate thermal characterization using a CFD code-case study of plastic packages, IEEE Transactions on Components, Packaging, and Manufacturing Technology: Part A 18 (4) (1995) 732-738. 
[41] J. Pharoah, On the permeability of gas diffusion media used in PEM fuel cells, Journal of Power Sources 144 (1) (2005) 77 - 82.

[42] Y. Elesin, M. F. Madsen, T. K. Petersen, Topology Optimization based homogenization technique for stack designs with complex geometry, Proceedings of 11th European SOFC \& SOEC Forum 2014 (July) (2014) B11.15-B11.23.

[43] R. Shah, A. London, Chapter VII - Rectangular Ducts, in: R. Shah, A. London (Eds.), Laminar Flow Forced Convection in Ducts, Academic Press, 196 - 222, 1978.

[44] J. H. Nam, D. H. Jeon, A comprehensive micro-scale model for transport and reaction in intermediate temperature solid oxide fuel cells, Electrochimica Acta 51 (17) (2006) $3446-3460$.

[45] F. P. Incropera, D. P. DeWitt, Fundamentals of Heat and Mass Transfer, John Wiley \& sons, 1999.

[46] A. Leonide, SOFC modelling and parameter identification by means of impedance spectroscopy, Ph.D. thesis, doi:10.5445/KSP/1000019173, 2010.

[47] A. Nakajo, Z. Wuillemin, D. Favrat, et al., Simulation of thermal stresses in anodesupported solid oxide fuel cell stacks. Part II: Loss of gas-tightness, electrical contact and thermal buckling, Journal of Power Sources 193 (1) (2009) 216-226.

[48] L. Blum, An analysis of contact problems in solid oxide fuel cell stacks arising from differences in thermal expansion coefficients, Electrochimica Acta 223 (2017) $100-108$.

[49] T. T. Molla, K. Kwok, H. L. Frandsen, Efficient modeling of metallic interconnects for thermo-mechanical simulation of SOFC stacks: Homogenized behaviors and effect of contact, International Journal of Hydrogen Energy 41 (15) (2016) 6433 -6444 .

[50] T. T. Molla, K. Kwok, H. L. Frandsen, Modeling the Mechanical Integrity of Generic Solid Oxide Cell Stack Designs Exposed to Long-term Operation, Fuel Cells 19 (1) (2019) 96-109. 
[51] K. Kwok, D. Boccaccini, A. H. Persson, H. L. Frandsen, Homogenization of steady-state creep of porous metals using three-dimensional microstructural reconstructions, International Journal of Solids and Structures 78-79 (2016) 38 46.

[52] W. Tian, L. Qi, C. Su, J. Zhou, Mean-field homogenization based approach to evaluate macroscopic coefficients of thermal expansion of composite materials, International Journal of Heat and Mass Transfer 102 (2016) 1321 - 1333.

[53] A. K. Miller, Thermal expansion coefficients for laminates obtained from invariant lamina properties, Fibre Science and Technology 13 (5) (1980) 397-409.

[54] D. Roylance, Laminated composite plates, Massachusetts Institute of Technology Cambridge .

[55] H. L. Frandsen, T. Ramos, A. Faes, M. Pihlatie, K. Brodersen, Optimization of the strength of SOFC anode supports, Journal of the European Ceramic Society 32 (5) (2012) 1041-1052.

[56] X.-Y. Miao, M. Navasa, H. L. Frandsen, Modelling of local interfacial failure in solid oxide cell stacks (paper in preparation) .

[57] Combined radiation and conduction heat transfer in high temperature fiber thermal insulation, International Journal of Heat and Mass Transfer 40 (9) (1997) 2241 2247.

[58] VDM Metals, VDM Crofer APU 22, https://www. vdm-metals. com, accessed: 2018-02-15, 2010.

[59] K. Daun, S. Beale, F. Liu, G. Smallwood, Radiation heat transfer in planar SOFC electrolytes, Journal of Power Sources 157 (1) (2006) $302-310$.

[60] NETZSCH, https://www.netzsch-thermal-analysis.com, accessed: 2018-02-15, 2018.

[61] T. Molla, F. Greco, K. Kwok, P. Zielke, H. Frandsen, Development of High Temperature Mechanical Rig for Characterizing the Viscoplastic Properties of 
Alloys Used in Solid Oxide Cells, Journal of Testing and Evaluation 46 (5) (2018) 1918-1929.

[62] D. Ni, B. Charlas, K. Kwok, H. Frandsen, Mechanical Properties of Ni-YSZ Anode Materials for Solid Oxide Fuel Cells, in: 39th Int. Conf. Expo Adv. Ceram. Compos., 2015.

[63] A. Nakajo, J. Kuebler, A. Faes, U. F. Vogt, H. J. Schindler, L.-K. Chiang, S. Modena, J. V. herle, T. Hocker, Compilation of mechanical properties for the structural analysis of solid oxide fuel cell stacks. Constitutive materials of anode-supported cells, Ceramics International 38 (5) (2012) 3907 - 3927.

[64] M. Mori, T. Yamamoto, H. Itoh, H. Inaba, H. Tagawa, Thermal Expansion of NickelZirconia Anodes in Solid Oxide Fuel Cells during Fabrication and Operation, Journal of The Electrochemical Society 145 (4) (1998) 1374-1381.

[65] A. Petric, H. Ling, Electrical conductivity and thermal expansion of spinels at elevated temperatures, Journal of the American Ceramic Society 90 (5) (2007) $1515-1520$.

[66] B. Sun, R. A. Rudkin, A. Atkinson, Effect of Thermal Cycling on Residual Stress and Curvature of Anode-Supported SOFCs, Fuel Cells 9 (6) (2009) 805-813.

[67] J. Kováik, L. Marsavina, E. Linul, Poissons Ratio of Closed-Cell Aluminium Foams, Materials $11(10)$.

[68] H. Frandsen, M. Makowska, F. Greco, C. Chatzichristodoulou, D. Ni, D. Curran, M. Strobl, L. Kuhn, P. Hendriksen, Accelerated creep in solid oxide fuel cell anode supports during reduction, Journal of Power Sources 323 (2016) 78 - 89. 